\title{
Variedades de capitalismo e complementaridades institucionais: uma análise da política petrolífera brasileira e da viabilidade do "Projeto Pré-Sal"
}

FrANCISCO EBELING

CARL Von OsSietzy Universität Oldenburg / Instituto de ECONOMia, Berlin, Alemanha

\section{Resumo}

O objetivo deste artigo é analisar a política petrolífera brasileira e, mais especificamente, a viabilidade do "projeto pré-sal" (Almeida, 2013), à luz da literatura das variedades de capitalismo, com especial ênfase no conceito de "complementaridades institucionais", que é fundamental nessa vertente teórica. A política petrolífera brasileira, na realidade, é uma coletânea de políticas públicas específicas, que são coordenadas pela política energética. Diante do desafio imposto pelo "projeto pré-sal", essas políticas públicas têm passado e continuarão passando por um processo de reavaliação e redimensionamento para que possam ser implementadas e executadas em uma escala mais adequada. Em muitos casos, as políticas públicas são reavaliadas e redimensionadas em conjunto, de maneira a avaliar se suas respectivas metas e instrumentos são compatíveis entre si. Argumenta-se que esse processo de reavaliação e redimensionamento pode ser interpretado como uma busca por "complementaridades institucionais". Em outras palavras, os tomadores de decisão almejariam criar ou aumentar sinergias entre as políticas, de forma que estas "aumentassem seus retornos" de forma recíproca, em linha com Hall e Soskice (2009). No artigo, é feita referência também a perspectivas alternativas sobre as complementaridades institucionais - como as de Becker (2007), Crouch (2009), Amable (2009) e Peck e Theodore (2007) - para analisar se políticas como a energética, a ambiental, a educacional, a de financiamento, a macroeconômica, a industrial, a externa e a de comércio exterior encontram-se calibradas para que os objetivos do "projeto pré-sal" possam ser atingidos. Com base na análise, conclui-se que, embora existam sinais contraditórios, a tendência é que o "projeto pré-sal" seja sucedido no longo prazo, ainda que em um ritmo mais lento e em um patamar inferior ao que esperavam inicialmente as autoridades brasileiras. Nesse contexto, os desdobramentos políticos e econômicos da Operação Lava Jato e a queda dos preços do petróleo são interpretados como "choques exógenos", que afetam temporariamente a busca por complementaridades institucionais, mas que não inviabilizam o "projeto pré-sal". Palavras-chave: "Projeto pré-sal". Variedades de capitalismo. Complementaridades institucionais. Políticas públicas.

\section{Varieties of capitalism and institutional complementarities: an analysis of Brazil's oil policy and the feasibility} of the "Pre-Salt Project"

\begin{abstract}
This paper aims to analyze Brazil's oil policy and, more specifically, the feasibility of the "Pre-salt Project" (Almeida, 2013) from the point of view of Varieties of capitalism (VOC) and with a special emphasis on the concept of "institutional complementarities", which is essential to this kind of literature. It is argued that Brazil's oil policy is actually a combination of specific public policies, which are ultimately coordinated by the energy policy. Faced with the challenge posed by the "pre-salt project", these public policies have experienced and will continue to experience a process of reevaluation and resizing so that their implementation can be carried out on a more appropriate scale. In many cases, these public policies are jointly reevaluated and resized in order to assess whether their respective goals and tools are mutually compatible. It is argued that this task can be interpreted as a search for "institutional complementarities". In other words, decision makers seek to strengthen or create synergies between public policies, so as to "increase each other's returns", in line with that set out in Hall and Soskice (2009). The article makes reference to alternative perspectives on institutional complementarities - such as Becker (2007), Crouch (2009), Amable (2009) and Peck and Theodore (2007) - to examine whether public policies such as energy, the environment, education, financing, macroeconomics, industry and foreign trade are prepared to meet the needs of the "pre-salt project". Based on this analysis, the conclusion is that there is a tendency for the "pre-salt project" to succeed in the long term, although at a slower pace and to a level below that expected initially by the government. In view of this, the political and economic implications of the "Operação Lava Jato" and the fall in oil prices are interpreted as "exogenous shocks" that temporarily affect the search for institutional complementarities, but do not represent a serious risk to the "pre-salt project".
\end{abstract}

Keywords: "Pre-salt Project". Varieties of Capitalism. Institutional Complementarities. Public policies.

\section{Variedades de capitalismo y complementariedades institucionales: un análisis de la política petrolera brasileña y de la viabilidad del "Proyecto Pre-Sal"}

\section{Resumen}

El objetivo de este artículo es analizar la política petrolera brasileña y, más específicamente, la viabilidad del "proyecto pre-sal” (Almeida, 2013), a la luz de la literatura de las variedades de capitalismo, con especial énfasis en el concepto de "complementariedades institucionales", que es crucial en esta línea teórica. En realidad, la política petrolera brasileña es una colectánea de políticas públicas específicas, las cuales son coordinadas por la política energética. Ante el desafío planteado por el "proyecto pre-sal", estas políticas públicas han pasado y seguirán pasando por un proceso de revaluación y cambio de tamaño para que puedan ser implementadas y ejecutadas en una escala más apropiada. En muchos casos, las políticas públicas son revaluadas y cambian de tamaño simultáneamente, con el fin de evaluar si sus respectivas metas e instrumentos son compatibles entre sí. Se argumenta que este proceso de revaluación y cambio de tamaño puede ser interpretado como una búsqueda de "complementariedades institucionales". En otras palabras, los tomadores de decisiones anhelarían crear o aumentar sinergias entre las políticas, para que estas políticas "aumentaran sus retornos" mutuamente, de acuerdo con Hall y Soskice (2009). En el artículo, se hace referencia también a perspectivas alternativas acerca de las complementariedades institucionales - como las de Becker (2007), Crouch (2009), Amable (2009) y Peck y Theodore (2007) - para analizar si políticas como la energética, la ambiental, la educacional, la de financiación, la macroeconómica, la industrial, la externa y la de comercio exterior se calibran para que los objetivos del "proyecto pre-sal" puedan lograrse. Con base en el análisis, se concluye que, aunque hay señales contradictorios, la tendencia es que el "proyecto pre-sal" tenga éxito a largo plazo, aunque a un ritmo más lento y con un nivel inferior al previsto inicialmente por las autoridades brasileñas. En este contexto, los acontecimientos políticos y económicos de la "Operação Lava Jato" y la caída de los precios del petróleo se interpretan como "choques exógenos", que afectan provisionalmente la búsqueda de complementariedades institucionales, pero que no hacen inviable el "proyecto pre-sal".

Palabras clave: "Proyecto pre-sal”. Variedades de capitalismo. Complementariedades institucionales. Políticas públicas. 


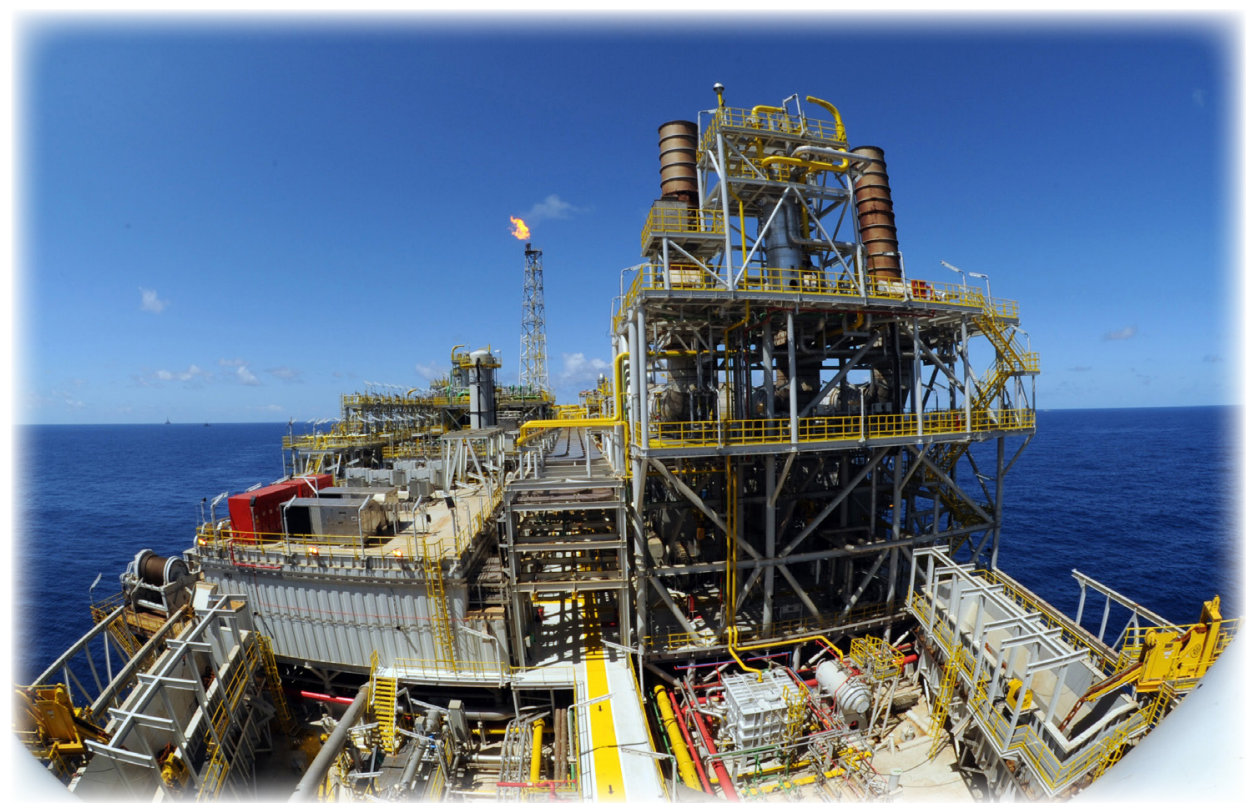

\section{INTRODUÇÃO}

A aprovação da Lei 12.351/2010, que instituiu o modelo de partilha de produção para campos não-licitados do pré-sal pode ser considerada o auge de uma estratégia desenhada durante o Governo Lula (2003-2010) para que o Estado retomasse o planejamento no setor petrolífero. Neste sentido, destacam-se iniciativas como a implementação de políticas de recursos humanos, tecnológicas no âmbito do PROMINP e a reintrodução da política de compras nacionais. De fato, esta tendência já tinha se iniciado sob os procedimentos licitatórios instituídos pela Lei do Petróleo de 1997, herdada do governo Fernando Henrique Cardoso, o que deixa margens quanto à pertinência de se ter aprovado o modelo da partilha em $2010^{1}$. Não obstante, em um contexto em que se antevia a possibilidade do país tornar-se um grande exportador de petróleo², e em que era iminente a implementação do arranjo contratual da partilha ${ }^{3}$, Pinto Junior $(2012$, p. 1) argumenta que:

(...) é indispensável a formulação e coordenação de políticas em bases inteiramente novas. As históricas diretrizes de políticas, antes voltadas para a redução da dependência das importações de petróleo, necessitam agora ser concebidas para a consolidação de uma posição relevante de exportador no mercado internacional. Dada a importância dos recursos petrolíferos do pré-sal, os desafios vão além da política energética, requerendo maior coordenação entre as políticas macroeconômica, industrial, tecnológica, ambiental, de formação de recursos humanos, de defesa e de política externa.

Em perspectiva análoga, Almeida (2013) compreende que o que chama de "projeto pré-sal", que constituiria "atualmente o principal desafio estratégico para o Brasil" requer "a mobilização de recursos humanos, financeiros, tecnológicos e também políticos numa escala sem precedentes". Em 2013, a Agência Internacional de Energia estimava que, até 2035, a escala da produção de petróleo no Brasil poderia ser aumentada entre 3 e 4 vezes. Se, em 2013, o país produzia, em média, 2,1 milhões de barris por dia, essa cifra poderia chegar até 7 milhões em 2035, em um cenário bastante otimista. No entanto, em função dos desdobramentos da operação Lava Jato - que teve um importante impacto sobre a cadeia de fornecedores de bens e serviços - e da queda dos preços do petróleo - que reduziu drasticamente a formação de caixa da Petrobras -, estima-se que, no

\footnotetext{
* Fonte da imagem: Flickr. Disponível em <https://www.flickr.com/photos/64663239@ N05/6172448624>. Acesso em 25 maio 2016.

${ }^{1}$ Ver Hernandez-Perez (2010).

2 Possivelmente, entre 2,5 e 3,5 milhões de barris diários poderão ser exportados em 2035, segundo a Agência Internacional de Energia (IEA, 2013).

${ }^{3}$ A primeira rodada de licitação sob a partilha, na qual foi leiloado o campo de Libra, foi realizada em 2013.
} 
período 2020-2030, a companhia tem potencial para produzir em média entre 3 e 4 milhões de barris por dia. Não obstante, sabe-se que, em ambas as previsões, os recursos necessários para extrair o petróleo do pré-sal - sejam estes físicos, humanos ou bens de capital - também precisarão crescer em uma escala sem igual, muitas das vezes diminuindo os recursos que permitiriam que a Petrobras atuasse em outras frentes. Neste sentido, Almeida $(2013$, p. 1) alerta que:

(...) para viabilizar esta expansão, o país deverá trilhar caminhos perigosos e arriscados. A velocidade que se pretende impor à caminhada não deixa margem para erros. Qualquer pequena barbeiragem pode levar a um acidente grave, dado o risco de se passar direto pelas curvas sinuosas que deverão ser trilhadas.

Em resumo, o que Almeida (2013) chama de "projeto pré-sal" representa um imenso desafio à capacidade do Estado de coordenar um número muito grande de políticas, tais como: energética, ambiental, macroeconômica, industrial, educacional (de recursos humanos), tecnológica, defesa, externa, regulatória, de logística (sobretudo portuária), tributária, de Comércio Exterior e de financiamento. Nesse complexo de políticas, a política energética é a que tende coordenar as demais.

A literatura das políticas públicas (SARAVIA, 2006; HOWLETT, RAMESH e PERL, 2013) costuma utilizar a imagem do "ciclo das políticas públicas" para descrever como surgem e evoluem as políticas públicas. Esse ciclo, usualmente, é constituído ao menos de 6 etapas: agenda, elaboração, formulação, implementação, execução e avaliação ${ }^{4}$. Nesse diapasão, a exploração do pré-sal - que ocorrerá não só na modalidade contratual da partilha5 -, irá requerer que uma série de "ciclos de políticas públicas" ocorra em paralelo. Mais precisamente, uma série de políticas públicas que já existem têm passado e continuarão a passar por um processo de reavaliação e redimensionamento de forma que possam ser executadas em uma escala mais adequada para enfrentar o desafio apresentado pela expansão da produção de petróleo no Brasil. Em muitos casos, surgem novas políticas públicas para preencher algumas lacunas, sobretudo no âmbito das políticas industrial e educacional (recursos humanos), com seus respectivos "ciclos de políticas públicas". O que aumenta a complexidade desse processo de reavaliação e redimensionamento é o fato que, entre muitas dessas políticas, existem importantes interseções e relações de dependência, o que implica na necessidade de que essa atividade seja realizada de forma sistêmica e conjunta. Se em algumas dessas políticas e interseções foi possível fazê-lo de forma relativamente pacífica e produtiva, alguns conflitos entre atores estratégicos dentro e fora da burocracia têm interditado outros processos de reavaliação e redimensionamento. Um bom exemplo do primeiro caso é a relação entre a política energética e a ambiental - como se verá na terceira seção -, enquanto um exemplo do segundo caso, a relação que existe entre a energética e a macroeconômica - como se verá na quinta seção.

Uma interpretação é que esse processo de reavaliação e redimensionamento das interseções entre as referidas políticas públicas se assemelha bastante à forma como surgem as "complementaridades institucionais", que é o conceito central da literatura das variedades de capitalismo de Hall e Soskice (2009). Nesse contexto, vale ressaltar que a definição de North (1991) do que são e para que servem as instituições ${ }^{6}$ é suficientemente ampla e flexível para contemplar também as políticas públicas. Por sua vez, Pierson (2006) e Fiani (2013) vão mais além e defendem que as políticas públicas podem também ser definidas como instituições. Dessa forma, seguindo esses autores, políticas públicas poderiam ser consideradas complementares no sentido de Hall e Soskice (2009). Assim, quando instituições governamentais ou atores estratégicos envolvidos na "policy-making" conseguem cooperar e agir de forma razoavelmente coordenada, as políticas públicas tendem a ser complementares.

Entretanto, o argumento desenvolvido ao longo do artigo não se atém somente à visão de Hall e Soskice (2009) do que são e como se formam "complementaridades institucionais". Diferentemente dos autores, que veem as instituições em equilíbrio, neste artigo, considera-se que os conflitos, as tensões e as contradições que ocorrem quando as políticas públicas acima mencionadas são reavaliadas e redimensionadas - em muitos casos sem sucesso -, demandam leituras mais críticas do conceito, como as de Becker (2007), Amable (2009), Crouch (2007), ou até mesmo a de Peck e Theodore (2007). Assim, por outro lado, a existência (inexistência) de complementaridades institucionais nas acepções alternativas do termo pode facilitar (dificultar)

\footnotetext{
${ }^{4}$ De acordo com Saravia (2006), essas etapas tendem a ser encontradas nos "ciclos das políticas públicas", mas não necessariamente na ordem exata.

5 A maior parte do petróleo do pré-sal nas próximas décadas virá de campos sob o contrato de concessão. Contudo, a tendência a longo prazo é que a maior parte do petróleo daquela camada será extraída sob a modalidade contratual da partilha. Além disso, exatamente 5 bilhões de barris serão extraídos sob a assim chamada "Cessão Onerosa", como será visto adiante.

${ }^{6}$ De acordo com o North (1991, p. 2), as instituições são as "restrições criadas pelos humanos para estruturar a interação política, econômica e social. Estas consistiriam tanto de restrições informais (sanções, tabus, costumes, tradições e códigos de conduta) quanto de regras formais (constituições, leis, direitos de propriedade).
} 
os supracitados processos de reavaliação e redimensionamento das políticas públicas que compõem a "política petrolífera do país", dos quais depende o sucesso do "projeto pré-sal". Este artigo dedica-se a analisar se no caso do "projeto pré-sal" predominam complementaridades institucionais - ainda que em formação -, ou se há mais casos onde estas não existem. Uma hipótese é que, quanto mais complementaridades institucionais existirem entre as políticas que compõem o "projeto pré-sal", maior a propensão ao seu sucesso.

O restante deste artigo está estruturado da seguinte forma: na primeira seção, é feita uma breve apresentação da literatura das variedades de capitalismo e de suas principais características; na segunda seção, analisa-se de que forma essa literatura precisa ser tratada para que seja possível descrever as características institucionais do setor petrolífero brasileiro. Já na terceira seção, descreve-se, com base no exemplo da relação entre a política ambiental e a energética, um típico processo de reavaliação e redimensionamento bem sucedido, onde as complementaridades institucionais tendem a emergir de forma lenta. Na próxima seção, são feitas duas descrições de relações entre políticas públicas em que a prévia existência de complementaridades institucionais - em várias acepções do termo - leva a crer que o "projeto pré-sal" será bem sucedido. Na quinta seção, descrevo a relação entre políticas públicas em que a aparente ausência de complementaridades institucionais sugere que o processo de reavaliação e redimensionamento se vê diante de um impasse, o que tende a dificultar a consecução dos objetivos do "projeto pré-sal". Finalmente, na última seção, é discutida a possibilidade da formação de "complementaridades institucionais" com instituições internacionais, tomando-se como exemplos as políticas externa e de Comércio Exterior.

\section{A LITERATURA DAS VARIEDADES DE CAPITALISMO E SUAS PRINCIPAIS CARACTERÍSTICAS}

A literatura das variedades de capitalismo - tal como esta é apresentada por Hall e Soskice (2009) - possui antecedentes teóricos muito antigos. Segundo Streeck (2010, p. 10), Karl Marx, que é considerado um dos primeiros teóricos que previram a convergência capitalista, já reconhecia, em alguma medida, as diferenças entre os capitalismos nacionais ${ }^{7}$. Para Van der Pijl, os argumentos de Karl Polanyi referentes ao duplo movimento teriam significado análogo, porque "como cada sociedade resolve os problemas resultantes da expansão do mercado e da concomitante expansão da proteção social em direção a áreas sensíveis da terra, do trabalho e da moeda de formas distintas, confrontamo-nos não com um, mas com muitos capitalismos" (2009, p. 114, tradução livre).

Mesmo com a força avassaladora das teorias sobre a convergência neoliberal, Jackson e Deeg (2006) argumentam que, desde os anos 1980, ganhava força na academia a convicção de que diferentes variações ou sistemas de capitalismo poderiam ter um bom desempenho econômico, institucional e político. Em um contexto em que se ocorria o que Diniz (2007) chama de

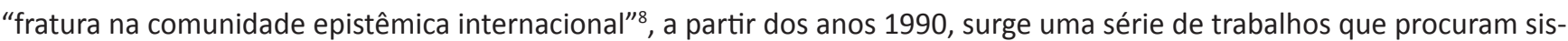
tematizar teoricamente essas diferenças nacionais, que fazem parte de uma tradição que Jackson e Deeg (2006) chamam de "capitalismos comparados". De forma alternativa, esta pode também ser chamada de "análise institucional comparativa". Jackson e Deeg, que empreenderam o monumental trabalho de "comparar os capitalismos comparados", argumentam que cada abordagem agruparia uma série de "building blocks" de acordo com os objetivos da análise e da respectiva ênfase téorica. Alguns dos autores que se destacam na tradição dos capitalismos comparados são: Esping-Andersen (1990), Albert (1993), Whitley (1999), Morgan (2005), Fligstein (2001), Boyer (2009) e Amable (2009).

\footnotetext{
${ }^{7}$ Nesse sentido, o autor diferencia "Marx, o teórico do capitalismo" de "Marx, o historiador econômico" (Streeck, 2010, tradução livre). Se para o primeiro, as principais características do capitalismo eram idênticas em toda a parte, para o segundo, as formas como se deu a acumulação primitiva do capital assumiu formas distintas nas nações.

${ }^{8}$ Se as décadas de 1980 e 1990 foram marcadas por um consenso em torno da primazia do mercado, os últimos 15 anos foram de refinamento do debate intelectual e acadêmico na esfera internacional, acirrando-se o clima de controvérsia e o conflito de visões acerca dos rumos do desenvolvimento capitalista (DINIZ, 2010, p. 16). A consequência desse refinamento, em que as ideias críticas em relação ao pensamento monolítico tornam-se cada vez mais ouvidas, foi uma fratura na comunidade epistêmica internacional econômica e política no sentido de Haas (1997). Assim, se até aproximadamente 15 anos atrás, os trabalhos críticos não eram as vozes dominantes no interior da comunidade epistêmica, atualmente os trabalhos de autores como Chang (2004; 2008; 2010), Crouch (2011), Evans (2004; 2006; 2008), HAY, LISTER e MARSH (2005), Rodrik (2011), Reinert (2007), Stiglitz (2010) e Amsden (2007), dentre outros, têm sido cada vez mais trazidos para o centro do debate. Esses trabalhos dedicam-se, sobretudo, a oferecer uma visão crítica sobre o processo de globalização e acerca do papel a ser desempenhado pelo Estado, criticando ainda a ideia da agenda única proposta pelo Consenso de Washington, com sua ênfase em reformas, liberalização dos preços da economia ou na abertura comercial.
} 
Nesse diapasão, consolidou-se como vertente central dessa literatura o trabalho de Hall e Soskice (2009). Em sua análise, os autores contrapõem dois tipos ideais de regimes de produção - as economias liberais de mercado, doravante $L M E s$-, e as economias de mercado coordenadas, doravante CMEs (DINIZ, 2007). O exemplo paradigmático do primeiro seriam os Estados Unidos; já do segundo, a Alemanha.

O ponto de partida da análise, segundo os autores, é a firma. Por isso, os textos fundadores da abordagem das variedades de capitalismo são considerados de nível "micro" e "médio" (LEOPOLDI, MANCUSO e IGLECIAS, 2010). Para Schmidt (2005), a ênfase de Hall e Soskice (2009) na firma teria como objetivo superar a dificuldade do institucionalismo histórico em explicar a assim chamada "human agency", dada a sua ênfase nas estruturas. Hall e Soskice buscariam, dessa forma, "micro-fundamentos" para o institucionalismo histórico.

Os autores têm uma visão relacional da firma, aplicando conceitos como "core competency" ou "dynamic capability" (HALL e SOSKICE, 2009). Para manterem-se competitivas e lucrativas ao longo do tempo, as empresas precisariam desenvolver uma série de competências e capacidades na relação com os demais atores do seu campo, como fornecedores, trabalhadores, credores, acionistas, clientes, sindicatos, governos, entre outros. Hall e Soskice (2009) condensam as relações das firmas com esses atores em 5 esferas institucionais: relações industriais, treinamento vocacional e educação, governança corporativa, relações inter-firmas e a relação entre trabalhadores e a firma. Para Streeck (2010), as LMEs e as CMEs divergiriam de acordo com a forma como as empresas coordenam as relações com essas esferas institucionais.

Surgem, daí, as complementaridades institucionais, onde as instituições são consideradas complementares quando a presença de uma (ou sua eficiência) aumenta o retorno da outra (HALL e SOSKICE, 2009). As complementaridades institucionais seriam diferentes em cada tipologia de capitalismo. Nos Estados Unidos, por exemplo, relações mais flexíveis entre trabalhadores e a firma seriam complementares a relações mais "financeirizadas" no âmbito da governança corporativa, que é a esfera onde as firmas se relacionam com seus financiadores. Na Alemanha, ideal-tipicamente essas duas relações seriam mais concertadas. Naquela economia política, a esfera do financiamento empresarial não seria tão "financeirizada" e a relação da firma com seus funcionários seria menos flexível. Quanto mais essas esferas institucionais se complementarem, maior a propensão ao sucesso da economia política. Tanto as esferas institucionais como as complementaridades institucionais configurariam a "armadura institucional" de cada tipologia de capitalismo (HANCKÉ, 2009). Embora Hall e Soskice (2009) considerem que as duas tipologias possam ter uma trajetória de sucesso, eles argumentam que, em termos de inovação, as LMEs se sairiam melhor no que tange às inovações radicais, ao passo que o segundo tipo se destacaria na gestação de inovações incrementais. Nesse sentido, cada tipologia possuiria também "vantagens institucionais comparativas", que teriam permitido às firmas instaladas em diferentes economias especializarem-se em nichos de atividades.

Outra característica importante da literatura das variedades de capitalismo de Hall e Soskice (2009) é a forma como é pensada a mudança institucional. Os autores concebem as economias nacionais como sistemas sujeitos a "choques exógenos", provenientes de mudanças tecnológicas, de novos produtos, e assim por diante. Como para esses autores a firma é o centro da análise, espera-se que estas responderão a estes choques readequando suas práticas, buscando restaurar a vantagem institucional comparativa. Ademais, as firmas contariam com a ajuda do Estado, que ajudaria a restaurar a forma de coordenação que existia entre as complementaridades institucionais antes dos "choques exógenos". Com base na experiência histórica de choques anteriores que puseram as complementaridades institucionais em risco, os autores acreditam que as economias nacionais possuem as ferramentas para restaurar o seu próprio equilíbrio institucional. Dessa forma, a mudança institucional ocorreria em equilíbrio. Para Boyer (2005), na abordagem das variedades de capitalismo, a "arquitetura institucional" de um país tende a ser invariável ao longo do tempo. Assim, segundo Hall e Thelen (2009), a mudança institucional na perspectiva de Hall e Soskice (2009) significa que a economia política navega constantemente de um equilíbrio para o próximo, sem, no entanto, perder as suas características centrais (HALL e THELEN, 2009).

De uma forma geral, a abordagem das variedades de capitalismo fornece um instrumental para pensar o capitalismo além do argumento da convergência neoliberal (HANCKÉ, 2009), estabelecendo uma "contra narrativa analiticamente plausível às visões monocromáticas da globalização" (PECK e THEODORE, 2007, p. 765, tradução livre). Peck e Theodore (2007) argumentam também que, em face do discurso pró-mercado dominante, esse referencial teórico chamou a atenção para que os sistemas econômicos, bem como as suas transformações, sejam socialmente inseridos. Mais além, este permite que se pense além das estruturas binárias - estatismo vs. mercado ou desenvolvimentismo vs. neo-desenvolvimentismo - alçando-se, ao primeiro plano, a análise das distinções entre regimes produtivos dentro das nações (DINIZ, 2007). 


\section{PARA UMA ANÁLISE DO SETOR PETROLÍFERO BRASILEIRO À LUZ DA LITERATURA DAS VARIEDADES DE CAPITALISMO}

Embora a literatura das variedades de capitalismo de Hall e Soskice (2009) seja bastante auspiciosa para contestar a tese da convergência neoliberal da forma como esta é apresentada por estes autores, ela não é compatível com uma análise exaustiva do setor petrolífero brasileiro. Nesse contexto, observa-se que a criação da Petrobras em 1953 fez parte de um projeto de desenvolvimento em que a centralidade do Estado era imprescindível (PINTO JUNIOR, 2007; ALVEAL, 1993; EVANS, 1979; FRANKE, 1993; FELIPE, 2010; LEITE, 2007). Como destaca Alveal (1993, p. 22):

(...) foi na liderança do monopólio estatal da indústria petrolífera que a Petrobras sedimentou extraordinário e peculiar aprendizado estratégico, político e econômico-empresarial, doméstico e cosmopolita, que permitiu ao Brasil enfrentar, de início, o poder econômico do cartel internacional do petróleo; e, mais tarde, os devastadores impactos das elevações dos preços de petróleo dos anos 1970, que inauguraram o atual cenário incerto da indústria mundial de petróleo.

Tendo em vista que, em alguns países, o Estado - e não a firma - é o "principal centro de poder" (LISTER e MARSH, 2005), o primeiro e mais importante aperfeiçoamento à literatura das variedades de capitalismo foi sugerido por Schmidt (2007), que propôs as assim chamadas "State-influenced market economies" (SMEs), cujo exemplo paradigmático seria a França. Essa variedade de capitalismo é um arquétipo muito adequado para compreender o funcionamento da indústria petrolífera brasileira antes de 1995, ano a partir do qual o setor começou a passar por grandes transformações.

Nesse ano, de acordo com Tolmasquim e Pinto Junior (2011), inaugurou-se a quarta fase da história da indústria de petróleo no Brasil, caracterizada pela abertura do mercado, que foi permitida pela flexibilização do monopólio da União sobre as jazidas e por uma profunda reestruturação institucional do setor. À época, foram 5 os fatores que motivaram a mudança institucional: (I) difusão de ideias liberalizantes; (II) baixos preços petrolíferos; (III) grande competição pelos investimentos das grandes petrolíferas por muitos países, em sua maioria dotados de reservas com elevado risco exploratório; (IV) baixa disponibilidade interna de tecnologia; e (V) ausência de recursos domésticos para realizar investimentos no setor.

Dessa forma, com a aprovação da lei 9.478/1997 - que ficou conhecida como a "lei do petróleo" - em 1997, foi instituído o contrato de concessão que estipulou que, mediante o pagamento de tributos, qualquer empresa que estabelecesse sede no Brasil passaria a poder adquirir o direito de explorar petróleo em um determinado bloco, por um período estipulado em contrato. Esses direitos passariam a ser outorgados em rodadas de licitações. Antes da primeira rodada de licitações, a assim chamada "rodada 0" concedeu à Petrobras o direito de escolher uma determinada quantidade de blocos. Entretanto, a abertura não foi acompanhada da privatização da Petrobras, somente da venda de um percentual das suas ações, próximo a $50 \%$. Nesse contexto, o que se chama de "golden share" da empresa foi mantido, o que preservou ao Estado a prerrogativa de seu controle gerencial. A referida lei criou também órgãos, como o CNPE e a ANP. Ao primeiro, caberia formular as políticas energéticas e propor o ritmo de realização de rodadas. Já ao segundo, caberia criar, executar e fiscalizar os contratos, divulgar informações e estatísticas, propor o cardápio de blocos das rodadas de licitações, defender a concorrência, além de outras funções. Finalmente, foi alterado o sistema tributário da indústria, onde os royalties passaram de $5 \%$ para $10 \%$ e foram criadas as assim chamadas "Participações Especiais".

Não obstante, as descobertas do pré-sal, anunciadas ao público em 2007, levaram o governo a aprovar a lei da partilha (Lei 12.351/2010). Foram igualmente 5 os fatores que levaram à revisão do marco regulatório - que se somou ao anterior ${ }^{9}-$, e, por conseguinte, a novas mudanças institucionais: (I) elevação dos preços petrolíferos nos anos 2000; (II) incapacidade, a nível mundial, de descobrir grandes reservas; (III) apropriação da capacidade de desenvolver a tecnologia necessária para explorar as recém-descobertas reservas do pré-sal; (IV) condições financeiras internas mais favoráveis ao investimento em exploração e produção de petróleo e gás; e (V) o projeto de tornar o pré-sal um vetor de desenvolvimento econômico e social para o país.

De acordo com a supracitada lei, a Petrobras será a operadora única dos blocos que, até então, não foram leiloados sob a modalidade contratual anterior, com uma participação mínima de $30 \%$ nos consórcios. Inspirado na experiência norueguesa,

\footnotetext{
${ }^{9}$ A lei do petróleo de 1997 continua vigente em campos fora do chamado "polígono pré-sal". Desde então, duas rodadas de licitação foram realizadas de acordo com as normas de licitação anteriores: a 11aㅡ e a 12a.
} 
a lei 12.351/2010 instituiu o "contrato de partilha", além de criar a PPSA, uma empresa estatal que cuidará dos interesses da União nos consórcios da Partilha. Além disso, a lei 12.351/2010 criou também um Fundo Social, que irá administrar a parte que couber à União nos contratos da partilha. Finalmente, o governo aprovou também uma lei para capitalizar a Petrobras, que produzirá 5 bilhões de óleo equivalente em troca de títulos do governo, como se verá adiante.

Em outubro de 2013, o governo leiloou, pela primeira vez, um bloco de acordo com os novos procedimentos instituídos pela lei 12.351/2010. O campo de Libra, do qual já se possui um nível bastante significativo de informação geológica com alguns poços já perfurados, é a segunda maior descoberta do século XXI no mundo, apenas atrás do campo gigante de Kashagan, no Cazaquistão. Espera-se que Libra contenha reservas entre 8 e 12 bilhões de óleo recuperável. O lance vencedor foi apresentado por um consórcio composto pela Petrobras (40\%), Royal Dutch Shell (20\%), Total (20\%), CNOOC (10\%) e CNPC (10\%). Essas empresas concordaram em oferecer um bid mínimo de 41,65\% de óleo do governo, além de pagar um bônus de assinatura de 15 bilhões de reais.

Após as duas ondas de mudanças institucionais - a primeira delas liberalizante e a segunda, até certo ponto, revertendo o ímpeto liberalizante da primeira onda -, o setor petrolífero brasileiro deixou de se encaixar na definição de Schmidt (2007) do que é uma SME. Mais do que tudo, o somatório dessas duas ondas de mudanças institucionais resultou em que o setor petrolífero brasileiro passasse a ter as características institucionais de um híbrido. A primeira onda de mudanças institucionais enxertou no setor características mais liberais de uma LME, mas não eliminou totalmente as características de uma SME. Ao longo dos últimos 10 anos, o setor petrolífero do país também adquiriu algumas características das assim chamadas "Mediterranean Market Economies"10 (MMEs), que, atualmente, são amplamente aceitas na literatura como uma quarta variedade de capitalismo. Nas MMEs, o Estado seria crucial por causa da fraqueza dos demais tipos econômicos de coordenação e governança. Para compensar essa fraqueza, o Estado auxiliaria as firmas tanto através da regulação como através de políticas industriais compensatórias. No setor petrolífero brasileiro, cabe ao Estado promover políticas industriais, já que o setor de bens e serviços não se encontra preparado para suprir toda a demanda da cadeia de valor do E\&P, principalmente em face das elevadas metas de conteúdo local atualmente exigidas. Não obstante, como o Estado brasileiro é o proprietário direto da maior parte das ações da Petrobras, e em função da importância dessa empresa e das demais instituições estatais na economia brasileira ${ }^{11}$, o setor petrolífero brasileiro é um híbrido onde predominam os traços de uma SME. Seu caráter híbrido parece se confirmar quando se analisa a relação da Petrobras com as 5 esferas institucionais consideradas por Hall e Soskice (2009):

A) Na primeira delas - "relações industriais" -, a firma barganha com os sindicatos e demais associações de classe as condições de trabalho e o ritmo do crescimento salarial. Hall e Soskice (2009) consideram, ainda, uma quinta esfera institucional, que chamam de "Relações com os empregados", que trata da relação da firma com seus próprios funcionários. Simplificando um pouco, embora esta primeira seja uma relação da firma com a indústria, faz sentido pensar que, no âmbito da Petrobras, "relações industriais" e "relações com os empregados" são muito similares. Quando a Petrobras negocia com o sindicato dos petroleiros, em grande medida, ela está negociando com seus próprios funcionários, o que é uma herança da época do monopólio. De uma forma geral, constata-se que as negociações entre o Sindicato dos Petroleiros e a direção da companhia tendem a ser permanentes e, muitas vezes, turbulentas.

B) A segunda esfera institucional considerada por Hall e Soskice (2009) é por eles chamada de "Treinamento e Educação". Trata-se da esfera onde a firma decide de que maneira irá treinar a mão de obra necessária, parte da qual ela mesma poderá formar. No que diz respeito a essa esfera, observa-se uma grande participação do Estado na formação de recursos humanos para a indústria de petróleo como um todo, não somente para a Petrobras. Destacam-se: o Programa de Mobilização da Indústria Nacional de Petróleo e Gás (PROMINP), criado pelo Governo Federal em 2003; e o Programa de Recursos Humanos da ANP, que se iniciou em 1999. A própria empresa dispõe de sofisticada instituição para treinar seus recursos humanos: a Universidade Petrobras.

C) A terceira esfera institucional é denominada "governança corporativa", que contempla, por exemplo, a relação da firma com seus financiadores. Embora o Estado seja o principal financiador da Petrobras, como explica Busch (2009,

\footnotetext{
${ }^{10}$ Propostas por Molina e Rhodes (2007, apud HANCKÉ, 2009, p. 15).

${ }^{11}$ De acordo com Alveal (1993), a Petrobras teria o peso econômico de um "Leviatã produtivo (Estado dentro do Estado)". Como explica Busch (2009, p. 123), no Brasil, a Petrobras funciona como o canal onde o governo eleito tem as possibilidades e os meios para intervir na economia.
} 
p. 129, tradução livre), "a bolsa é uma importante fonte de capital para a Petrobras. Suas ações constam entre as mais transacionadas. A empresa se compromete a ser transparente e a prestar contas ao órgão que supervisiona as ações e a seus acionistas." Assim, a cada trimestre, de acordo com os seus resultados, a Petrobras pode pagar ou não aos seus acionistas um dividendo como forma de remunerar a propriedade das ações. Nesse sentido, recentemente, ocorreram conflitos distributivos - entre a companhia e o Governo, de um lado, e os investidores privados, de outro - para os quais se atribuíram os piores resultados da companhia o fato de os preços dos combustíveis no Brasil não acompanharem o mercado internacional. Em função das pressões inflacionárias, o governo reluta em repassar as flutuações dos preços internacionais do petróleo aos consumidores brasileiros. Se reajustados, estes poderiam refletir em melhores resultados para os acionistas. Isso está em linha com o que explica Busch, para quem, na "Brasil S.A.", disse que seria comum que "as grandes empresas estatais abdiquem de elevar tarifas ou mantenham postos de trabalho mesmo que isso afete os lucros e os dividendos, o que não agrada os acionistas" (BUSCH, 2009, p. 123, tradução livre).

D) A quarta esfera institucional é chamada de "relações inter-firmas". Esta diz respeito à forma como a Petrobras se relaciona com as empresas que se situam na cadeia industrial do petróleo como prestadoras de serviços ou fornecedoras de bens e equipamentos. A tendência é que a Petrobras, enquanto operadora única no pré-sal sob a partilha, cada vez mais exerça posição de absoluto protagonismo nessa cadeia. Dessa forma, as "relações inter-firmas" são enviesadas a favor da Petrobras, que, na maior parte dos casos, consegue fazer valer suas decisões referentes a padrões de qualidade e prazos.

Ao contrário do que prevê a teoria das variedades de capitalismo, aqui se defende que o fato de o setor petrolífero brasileiro ser um híbrido - e não um tipo puro - não piora seu desempenho. Dessa forma, não tender à polarização (estritamente LME ou SME), mas sim à convergência institucional - com algumas características de ambos -, não diminui, obrigatoriamente, a eficiência dessa indústria. Nesse contexto, Kenworthy (apud HANCKÉ, 2009, p. 10) já havia demonstrado que o desempenho de países híbridos poderia ser tão bom quanto, ou inclusive melhor, do que o dos tipos puros ${ }^{12}$. Isso significa que, em uma primeira leitura, pouco importa para o desempenho do setor se instituições e políticas de um cunho mais liberal convivam e complementem instituições e políticas de cunho mais estatista.

Na realidade, como se verá mais adiante, o processo de hibridização das instituições do setor petrolífero brasileiro pode (I) contribuir para o desmantelamento das "complementaridades institucionais" que se pretende formar ou (II) contribuir para aperfeiçoar as complementaridades institucionais entre duas ou mais políticas.

\section{O SURGIMENTO DE “COMPLEMENTARIDADES INSTITUCIONAIS”: O EXEMPLO DA INTERSEÇÃO ENTRE A POLÍTICA ENERGÉTICA E A DE LICENCIAMENTO AMBIENTAL}

Na presente seção, parte-se da perspectiva de Becker (2007) para descrever o processo como as complementaridades institucionais normalmente são formadas, com base no exemplo da relação entre a política energética e a política ambiental. De acordo com Becker (2007), que defende a perspectiva dos sistemas abertos, as economias nacionais e suas instituições não necessariamente se formaram segundo algum plano deliberado ${ }^{13}$. Por outro lado, há pressões externas e internas para que suas características institucionais se organizem de forma sistêmica e funcional, o que possibilitaria a existência, em algum grau, de complementaridades institucionais. Não obstante, para Becker, o fato de uma organização institucional sistêmica e funcional ser desejável não significa que esta será alcançada. Em resumo, formar complementaridades institucionais é uma meta que é almejada, mas que não necessariamente é atingida.

Nos últimos anos, tem-se almejado aperfeiçoar a relação de complementaridade entre a política energética e a política ambiental porque esta última - ao menos no que diz respeito à política de licenciamento ambiental dos blocos que são ofertados nas rodadas de licitação - tende a dificultar a consecução da primeira. Nesse sentido, o bom funcionamento da

\footnotetext{
12 Segundo Crouch (2009), muitas vezes, o bom desempenho de uma LME como os Estados Unidos, em grande parte, deriva precisamente daquilo que o modelo exclui. De acordo o autor, nos Estados Unidos sob o neoliberalismo, aponta Crouch (2009), existe um poderoso setor militar em que o Estado tem papel central em coordenar o avanço tecnológico, fomentando e mantendo uma ampla rede de empresas fornecedoras e pesquisadoras

${ }^{13}$ Essa é uma tese discutível, haja vista a bem sucedida experiência histórica de países como a Coréia do Sul, o Japão e a Alemanha.
} 
política energética - que pode ser mensurado, por exemplo, através do ritmo de aumento da produção de petróleo e gás - requer celeridade nos procedimentos de licenciamento ambiental, sobretudo em uma época em que as metas de produção são bastante arrojadas.

Uma das características centrais do modelo que ainda regeu a 11a e a 12a rodadas de licitações é que não existe um licenciamento prévio na etapa de planejamento. Nesse sistema, a ANP licita as áreas em questão antes que o órgão ambiental responsável conceda as licenças (MARIANO, 2007). Como explica Teixeira (2008), é muito comum que o processo de licenciamento ambiental do ciclo operacional das atividades de perfuração de poços exploratórios seja superior a 18 meses. Já a perfuração exploratória em si, como mostra a autora, geralmente tem duração média de 3 meses. Dessa forma, além de poder acarretar em prejuízos econômicos e sociais, a morosidade do licenciamento ambiental pode ser interpretada como um obstáculo à consecução dos objetivos do que Almeida (2013) chama de "projeto pré-sal".

Ao menos desde 1998, têm sido conduzidas discussões visando à revisão das normas de licenciamento ambiental, capitaneadas pela ANP, pelo o MMA e pelo IBAMA. Desde então, busca-se implementar no Brasil a Avaliação Ambiental Estratégica $(A A E)$, a partir da bem sucedida experiência internacional em países como Nova Zelândia, Canadá, Reino Unido e Estados Unidos. Conforme Mariano (2007, p. 227), a Avaliação Ambiental Estratégica - AAE - é um "instrumento de política ambiental que tem por objetivo auxiliar (...) os tomadores de decisões no processo de identificação e avaliação dos impactos e efeitos (...) que uma dada decisão estratégica (..) poderia desencadear no meio ambiente e na sustentabilidade do uso de recursos naturais (...)". Teixeira (2008) argumenta que a abordagem da AAE tem como norte a busca pela eficiência do sistema de licenciamento e da gestão ambiental das atividades envolvidas com a cadeia de petróleo, o que requer instituições governamentais mais ágeis e eficazes. Conforme Teixeira (2008, p. 266-7) "o processo de adoção da AAE em etapas requer" ainda "a convergência dos processos de planejamento ambiental e de planejamento energético" e deve permitir a participação de "stakeholders" da sociedade civil que até então não eram ouvidos, como os pescadores ou outros representantes das comunidades ribeirinhas.

Em 2012, foi aprovada a Portaria Interministerial MMA/MME no 198 - 2012, que institui a "Avaliação Ambiental de Área Sedimentar - AAAS -, disciplinando sua relação com o processo de outorga de blocos exploratórios de petróleo e gás natural, localizados nas bacias sedimentares marítimas e terrestres, e com o processo de licenciamento ambiental dos respectivos empreendimentos e atividades". Com a AAAS, será possível fazer, já no processo de planejamento - e não ao longo das etapas de exploração e produção -, a avaliação ambiental de uma ou mais áreas de uma bacia sedimentar. Assim, os possíveis riscos serão conhecidos antes que a decisão de conceder os blocos seja tomada, de forma que áreas consideradas altamente sensíveis do ponto de vista da conservação da biodiversidade tenderão a não ser ofertadas. Cria-se, assim, um ambiente de maior confiabilidade, menores incertezas e complexidade para as agências governamentais, para as empresas e para a sociedade em geral. Com a AAAS, as decisões serão tomadas por um conjunto grande de instâncias governamentais interessadas. Ao invés de a arbitragem ser apenas realizada pelo IBAMA, serão consultados também a ANP, o ICMBIO, o MME, o MMA, o Ministério do Turismo e o da Pesca, os quais tomam a decisão se determinado bloco vai ou não ser ofertado de forma conjunta, olhando para um grupo muito mais amplo de variáveis.

O acima exposto processo de formação de uma relação de complementaridade entre a política energética e a política de licenciamento ambiental dos blocos que são ofertados nas rodadas de licitação é facilmente identificável com a perspectiva de Becker (2007), segundo a qual a busca por complementaridades institucionais é essencialmente um processo aberto. No entanto, a visão do autor acerca dessa busca não é compatível com a forma como Hall e Soskice (2009) enxergam a possibilidade de que ocorram mudanças institucionais, uma vez que o modelo de licenciamento ambiental até então vigente - extremamente deficitário e incompatível com as atuais necessidades da política energética - dificilmente pode ser descrito como estando em "equilíbrio"14. Tem-se, então, que, nas últimas décadas, as instituições que regem o licenciamento ambiental da exploração e produção de petróleo e gás têm passado por um processo contínuo e dinâmico - por vezes moroso - de aperfeiçoamento. Esse processo de aperfeiçoamento institucional é muito bem descrito pela forma de mudança institucional que Streeck e Thelen (2009) chamam de "estratificação" ${ }^{15}$. De acordo com os autores, essa modalidade de mudança institucional caracteriza-se por:

\footnotetext{
${ }^{14}$ Na melhor das hipóteses, como sugere Amable (2009), como estando em um "equilíbrio inferior".

${ }^{15}$ As outras 4 formas de mudança institucional na visão de Streeck e Thelen (2009) são: deslocamento, conversão, espalhamento e exaustão.
} 
(...) active sponsorship of amendments, additions, or revisions to an existing set of institutions. The actual mechanism for change is differential growth; the introduction of new elements setting in motion dynamics through which they, over time, actively crowd out or supplant by default the old system as the domain of the latter progressively shrinks relative to that of the former. (STREECK e THELEN, 2009, p. 120)

Em resumo, a mudança institucional por que tem passado a política de licenciamento ambiental da exploração de petróleo e gás é um processo gradual de substituição de uma coletânea de procedimentos que não mais se adequava às necessidades da política energético-petrolífera do país por outro que, a médio prazo, tenderá a melhor complementar esta última.

\section{DUAS MODALIDADES DE COMPLEMENTARIEDADES INSTITUCIONAIS QUE CONTRIBUEM PARA O SUCESSO DO “PROJETO PRÉ-SAL”: POLÍTICA DE FINANCIAMENTO E EDUCACIONAL}

A presente seção apresenta duas perspectivas alternativas às de Hall e Soskice (2009) sobre as "complementaridades institucionais". Nos dois casos, a forma como estas são formadas tendem a favorecer a consecução dos objetivos do "projeto pré-sal".

\section{Política de financiamento: o caso da (cessão onerosa)}

A primeira perspectiva alternativa sobre as complementaridades institucionais é a de Crouch (2009), para o qual é, empiricamente, muito mais relevante dizer que instituições são complementares quando uma instituição mais sólida "apoia" o funcionamento de outra mais frágil. Dessa forma, a obtenção de retornos crescentes através da interação institucional não necessariamente é recíproca, como o defenderiam Hall e Soskice (2009).

Com base no exemplo da Cessão Onerosa, aprovada mediante a lei 12.276, de 30 de junho de 2010, aqui se argumenta que a visão de Crouch (2009) acerca das complementaridades institucionais pode ser aplicada à análise da relação entre a política energética e a política de financiamento da Petrobras. De acordo com o artigo 10 da referida lei, a União foi autorizada a ceder onerosamente à Petrobras, em um período máximo de 12 meses, dispensada a licitação, o exercício das atividades de pesquisa e lavra de petróleo e demais hidrocarbonetos em áreas não concedidas localizadas no pré-sal não podendo a produção exceder 5 bilhões de barris equivalentes de petróleo. Como contrapartida pela referida cessão, o mencionado ato legal determinou que o pagamento devido pela Petrobras fosse efetivado, prioritariamente, em títulos da dívida pública mobiliária federal, precificados a valor de mercado (SOUSA, 2011). Segundo contrato aprovado pela CNPE e pela Petrobras em 2010, a Petrobras produzirá até 5 bilhões de barris de óleo equivalente nos campos de Tupi Sul, Florim, Tupi Nordeste, Guará Leste, Franco, lara e Peroba.

A capitalização da Petrobras através da Cessão Onerosa ocorreu em um cenário em que se antevia que a exploração do pré-sal iria aumentar vertiginosamente a escala de investimentos realizados pela Petrobras, sobretudo em Exploração e Produção. Um trabalho realizado por lootty e outros (2008) concluiu que, diante disso, haveria uma tendência a que aumentasse o endividamento de curto prazo da companhia. De fato, como mostra o gráfico 1 abaixo, até o ano de 2008 o indicador "\% endividamento curto prazo/endividamento total" encontrava-se razoavelmente elevado. 


\section{Gráfico 1}

“Percentual de endividamento de curto prazo sobre endividamento total” e capitalização total da Petrobras em R\$ bi

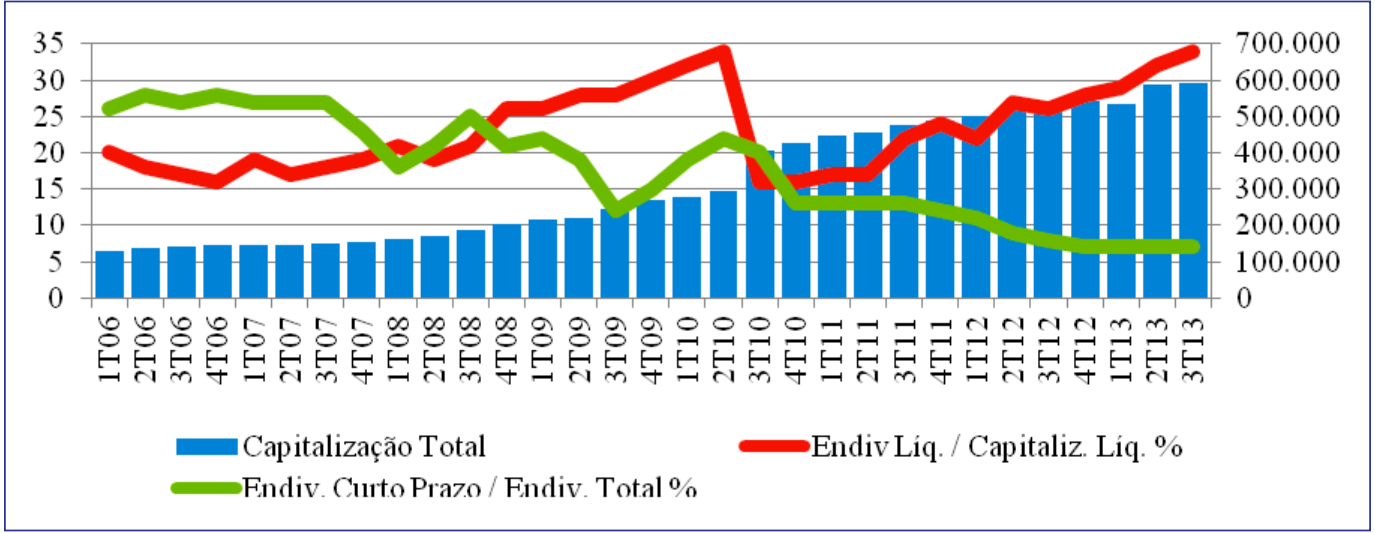

Fonte: Elaboração própria com dados da Petrobras.

Mas, a partir do segundo trimestre de 2010, esse indicador caiu a níveis muito mais baixos do que aqueles observados em 2008 , desde então abaixo da casa dos $15 \%$. Houve um salto substancial também no indicador "Capitalização total", que passou a margear a casa dos US\$ 250 bi, justamente a época em que ocorreu a capitalização da empresa através da cessão onerosa.

Voltando à análise de Crouch (2009) acerca das complementaridades institucionais, tem-se que a União - um conjunto de instituições financeira e economicamente muito fortes - concebeu a Cessão Onerosa como forma de "apoiar" uma instituição financeiramente mais fraca, a Petrobras, que tem um papel central no seu projeto de desenvolvimento. Mas, como mostra Bicalho, a Cessão Onerosa visou não somente à capitalização da Petrobras, mas também a um aumento da participação acionária do Estado "nesta mesma empresa, canalizando a maior parte dos ganhos possíveis para os cofres federais" (BICALHO, 2010). Dessa maneira, talvez seja possível argumentar que, embora essa tenha sido uma complementaridade institucional entre uma instituição mais forte e outra mais fraca, como sustentaria Crouch (2009), a Cessão Onerosa até certo ponto, visa a aumentar a reciprocidade entre os retornos crescentes, em linha com a perspectiva de Becker (2009). Nesse sentido, ao capitalizar a Petrobras, o Estado irá perceber uma parte maior das receitas oriundas da exploração petrolífera que, por sua vez, poderá ser destinada às diversas políticas públicas que este implementa, como por exemplo a educacional. Não obstante, vale destacar que recentemente os indicadores de endividamento da companhia voltaram a piorar de forma substancial, o que sinaliza que o Governo novamente pode optar por capitalizar a empresa.

\section{Política educacional}

A segunda perspectiva alterna sobre as complementaridades institucionais a que se alude nessa seção, a de Amable (2009), é aplicada à análise da relação entre a Petrobras e a política educacional do país. O que se chama de forma bastante genérica de "política educacional do país", na realidade, é uma coletânea muito complexa de políticas específicas, ações, planos, iniciativas e programas voltados para todos os tipos de educação pública do país, que abarcam desde as creches até a pós-graduação. Embora o estado da educação pública no país continue muito aquém do desejável, argumenta-se que está cada vez mais tem sido concebida de forma holística (KERSTENETZKY, 2012). Em outras palavras, o Estado tem reconhecido o caráter sistêmico da educação e assume que as interdependências entre os diversos níveis têm que se refletir nas diversas políticas educacionais que formula, elabora, implementa e executa.

A imagem de políticas educacionais concebidas de forma cada vez mais sistêmica é uma clara alusão às complementaridades institucionais na visão de Becker (2007), conforme foi visto na seção anterior. Nesse contexto, a aprovação do Projeto de Lei, que cria o Plano Nacional da Educação, aprofundaria a "sistematicidade" na política educacional do país, sobretudo em função da criação de mecanismos - como o investimento obrigatório de $10 \%$ do PIB - para atingir determinadas metas 
na área da educação. Uma interpretação análoga pode ser feita sobre a aprovação da nova lei dos royalties (Lei no 12.858), segundo a qual 75\% dos royalties dos campos cuja produção se iniciar em 2013 devem, obrigatoriamente, ser destinados à educação e $50 \%$ dos retornos do Fundo Social à educação e à saúde. Indo além, se a capacidade da "política educacional do país" de ofertar bons serviços educacionais for de fato majorada, criam-se ou reforçam-se as complementaridades institucionais entre esta política e outras, como a industrial e a de saúde. Nesse sentido, entende-se que a educação é um importante insumo para o sucesso dessas políticas, seja através da oferta de bons engenheiros (política industrial), seja através de uma melhoria da alimentação infantil nas creches (política de saúde).

Não obstante, aqui se argumenta que entre a Petrobras e algumas políticas educacionais existe o que Amable (2009) chamaria de "complementaridades institucionais dinâmicas", ainda que de forma muito sutil. Para o autor, a presença de uma forma institucional em uma área leva à adoção de uma forma institucional em outra. Dessa forma, haveria uma relação hierárquica entre as instituições complementares. Assim, quando se forma a agenda de políticas públicas, o setor petrolífero - a Petrobras e as demais instituições que neste atuam, como o MME - tem uma situação privilegiada em relação a outros atores sociais ou econômicos. Como esta é uma indústria extremamente importante para o país, sua demanda por recursos humanos tende a ser atendida de forma prioritária em relação a outras áreas. Assim, embora programas como o PRONATEC e o Ciência sem Fronteiras sejam políticas públicas transversais com múltiplos objetivos, seu foco principal é atender às necessidades do setor produtivo, onde a indústria do petróleo tem um papel extremamente destacado. Nesse contexto, as demandas do setor produtivo por políticas públicas, onde a Petrobras é provavelmente o ator estratégico mais destacado, tende a se refletir no desenho das políticas educacionais do país.

No entanto, Weiss (1998) argumenta que, para que ambos sejam robustos, é necessário que exista uma relação de reciprocidade entre o que chama de "distribucionismo" e o desenvolvimentismo. Por isso, já que programas como o PRONATEC e o Ciências sem Fronteiras fortalecem a capacidade da indústria petrolífera de fomentar o desenvolvimento econômico do país, indiretamente, geram-se complementaridades institucionais mais próximas daquelas propostas por Hall e Soskice (2009) ou por Becker (2007), porque as receitas geradas pela indústria petrolífera - sejam estas diretas ou indiretas - fortalecerão a capacidade distributiva do país a longo prazo.

\section{QUANDO A CRIAÇÃO DE COMPLEMENTARIDADES INSTITUCIONAIS É UMA TAREFA DIFÍCIL: POLÍTICA MACRÖCONÔMICA E INDUSTRIAL}

O propósito dessa seção é discutir relações de complementaridades institucionais que, por uma série de razões, são difíceis de formar ou, em uma primeira leitura, aparentam sê-lo. As políticas que exemplificam o argumento apresentado nessa seção são a macroeconômica, a industrial e a energética.

\section{Política macroeconômica}

Peck e Theodore (2007) argumentam que as características institucionais de uma economia nacional, tais como as complementaridades institucionais, podem coexistir em uma situação de desequilíbrio. Nesse sentido, os autores afirmam que "atores estratégicos podem mobilizar recursos para impor ou defender uma ordem não ótima, ineficiente ou pouco igualitária (PECK e THEODORE, 2007, p. 755, tradução livre)". Dessa forma, a possibilidade de que instituições aumentem o retorno uma da outra - isto é, que se complementem - pode ser severamente dificultada.

Um exemplo bastante contundente disso é a relação que existe entre a política energética e a política macroeconômica. Para que a consecução dos objetivos da política energética seja possível - como, por exemplo, aumentar expressivamente a produção de petróleo para algo entre 4 e 5 milhões de barris diários em 2020 -, é necessário o aporte de uma soma considerável de investimentos. Para tal, o BNDES estimava que, entre 2014 e 2017, cerca de 460 bilhões de reais seriam investidos para viabilizar a exploração e a produção de petróleo no Brasil. Estima-se que o consórcio vencedor irá desembolsar algo em torno de 100 a 200 bilhões de dólares para explorar Libra. 
Tipicamente, a indústria de petróleo consegue financiar seus investimentos com o próprio caixa que gera. No entanto, como se discutiu anteriormente, ao menos desde 2005 as preocupações com o nível da inflação levaram o governo a manter relativamente estáveis os preços dos derivados do petróleo, como a gasolina e o diesel, como pode ser visto no gráfico 2 abaixo. No mesmo período, também conforme o gráfico, os preços internacionais de referência (Brent) oscilaram bastante.

\section{Gráfico 2}

\section{Evolução dos preços dos derivados de petróleo no Brasil em R\$ (por litro) e do Brent em US\$ (por barril)}

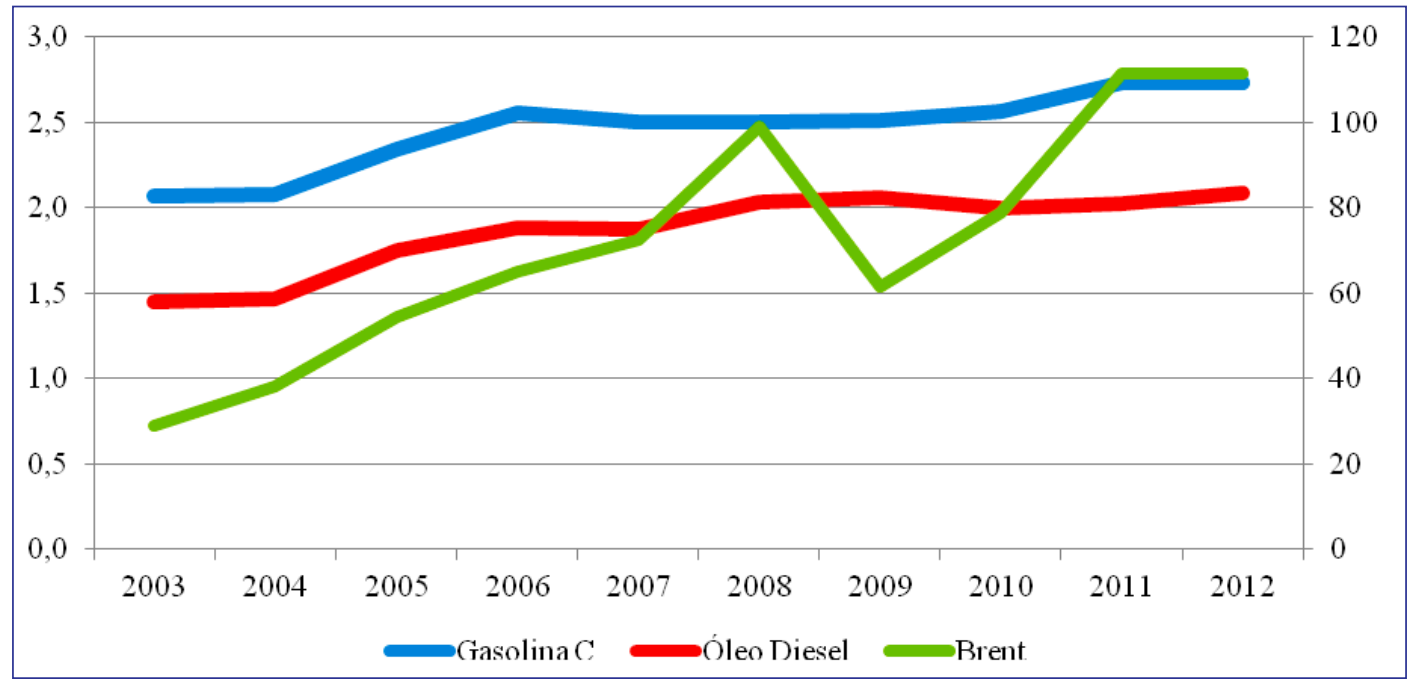

Fonte: ANP.

A Petrobras controla os preços dos derivados na porta da refinaria, setor o qual, na prática, é monopolista. Em função do "market share" da Petrobras Distribuidora (BR), diante do risco de sair do mercado as demais empresas atuantes no setor do downstream, não tem incentivos a elevar significativamente os preços dos derivados, mantendo-os ligeiramente acima dos custos e de uma pequena taxa de lucro. Assim, como mostram Colomer e Tavares (2012), por obrigar a companhia a não repassar para os preços as oscilações do câmbio e dos preços internacionais, a atual política de preço de combustíveis no Brasil tem criado estímulos negativos ao investimento na cadeia petrolífera. Como a maior parte da receita bruta auferida pela Petrobras é em função do preço dos derivados do petróleo, a empresa tem tido dificuldades para financiar as suas operações.

Outro exemplo do aparente descasamento entre os objetivos da política energética e os da macroeconômica é dado pelo bônus de assinatura que foi pedido pelo governo quando este licitou o campo de Libra em 2013 . Como os R\$ 15 bilhões pedidos devem ser pagos no ano inicial do contrato, quando descontada no tempo, essa soma tende a diminuir significativamente a atratividade - leia-se, a TIR - do projeto. Dessa forma, diminuiu-se a competição no leilão, o que também é um dos objetivos da política energética ${ }^{16}$. Essa elevada pedida foi feita em uma conjuntura em que era dominante no "mercado" a convicção de que o governo tinha dificuldades para fechar as suas contas. Diante disso, a política fiscal encontra-se atualmente apertada para aumentar o superávit primário com a motivação de "acalmar os mercados" e de "restaurar a confiança dos investidores". De uma forma geral, ao longo dos últimos anos, observa-se certa incongruência entre os objetivos e metas da política macroeconômica do país - ora expansionista, ora generosa com o capital financeiro - como o mostram Serrano e Summa (2012). Há dúvidas se uma política fiscal dominada pelo mantra dos "orçamentos equilibrados" e pelo imperativo de produzir superávits primários (Nadal, 2011) é compatível com a política energética/petrolífera do "projeto pré-sal”, já que a sua consecução depende de um forte esforço expansionista.

\footnotetext{
${ }^{16}$ Em uma interpretação alternativa, talvez seja possível argumentar que o objetivo da política energética nunca foi fomentar a competição no leilão de Libra, diante da possibilidade de acordos de bastidores prévios com as empresas vencedoras.
} 
Com base nesses dois exemplos, conclui-se que, à primeira vista, a política energética e a política macroeconômica parecem não estar alinhadas, o que sugere uma ausência de complementaridade institucional. O que torna a discussão mais complexa é que, em maio de 2014, a Petrobras ultrapassou a marca dos 500.000 barris produzidos no pré-sal, com a entrada em operação de duas novas plataformas (Cidade de Ilhabela e Cidade de Mangaratiba) e o início de operação dos 22 novos poços produtores, que serão interligados às plataformas já instaladas. Esse rápido aumento da produção, provavelmente, fará com que a empresa consiga monetizar de forma cada vez mais expressiva suas reservas no pré-sal. Isso significa que o impacto financeiro do congelamento dos preços dos derivados ou da elevada pedida do bônus de Libra será menor, o que parece amenizar os conflitos dentro da burocracia e a consequente ausência de complementaridade institucional entre a política energética e a macroeconômica.

Vale relembrar ainda que, quando o preço do Brent é baixo, mesmo se os preços dos combustíveis estivessem alinhados ao mercado internacional, o caixa gerado pela Petrobras com a venda de combustíveis seria muito menor, o que também torna toda a discussão em torno da existência ou não de complementaridades institucionais entre essas duas políticas muito complexa. Se esse fosse o caso, provavelmente, o governo encontraria outra forma de financiar a Petrobras, o que indica que, de forma geral, o Estado brasileiro e a Petrobras são instituições que sempre tenderam a se complementar. Assim, sobretudo na época do monopólio, as instituições estatais tenderam a alinhavar as suas metas e objetivos, a despeito de eventuais conflitos em situações específicas.

\section{Política industrial e de conteúdo local}

Talvez a abertura de 1997 tenha alterado um pouco essa situação através do acima mencionado processo de hibridização, o qual enxertou instituições de um cunho mais liberal no setor petrolífero brasileiro. Mais especificamente, a liberalização e a hibridização de algumas instituições criou a possibilidade de que novos atores agissem politicamente para fazer valer seus interesses. Ao enfatizar que os atores tendem a cooperar e se coordenar para manter o equilíbrio institucional de uma economia nacional, como ressalta Streeck (2010), a literatura das variedades de capitalismo de Hall e Soskice (2009) expurga de sua análise algumas das características centrais que definem o que é uma economia capitalista como, por exemplo, os problemas referentes à distribuição, à exploração do trabalho pelo capital, à política, ao poder e ao conflito. Ao trazer de volta a política e o poder para a literatura das variedades de capitalismo, tem-se que os atores estratégicos podem (I) mobilizar seu capital político para sugerir outra forma de tornar instituições complementares ou (II) mobilizar seu capital político para propor a substituição completa ou parcial de uma instituição por outra, o que acarretaria novas relações de complementaridades ou uma tendência ao desequilíbrio institucional.

De acordo com Streeck, "no capitalismo a política (...) é sobre a sucessiva subversão e reorganização da ordem pública" (...) e sobre a "a de- e reconstrução de limites institucionalizados à busca egoísta por interesses privados" (STREECK, 2012, p. 680, tradução livre). A história da indústria de petróleo mostra que as grandes empresas, tipicamente, procuram entrelaçar essa reconstrução com as suas práticas de "rent-seeking". Especialmente nos Estados Unidos, as majors se articulam politicamente e, na prática, interditam o debate sobre a regulação pública das suas atividades com o argumento de que geram empregos e que distribuem renda.

Voltando ao Brasil, de 1997 a 2003, isto é, da 1a à 4ạ rodadas de licitação, a ANP tratou o assunto do conteúdo local como um período de "presença de incentivos", onde sua oferta era livre, sem necessidade de observar percentuais mínimos e máximos (QUINTANS, 2010). Da quinta rodada em diante, realizada em 2003, o conteúdo local passou a ser mais um critério de apuração nos leilões, onde se estipularia um conteúdo local mínimo para cada fase (exploração e desenvolvimento da produção). Instituindo a obrigatoriedade dessas metas, o governo pretendia aumentar a atividade da indústria brasileira e potencializar a geração de empregos no país. Talvez seja possível afirmar que, com a reintrodução das metas de conteúdo local, buscou-se "reorganizar a ordem pública subvertida pelo capitalismo". Nos anos que se seguiram, as empresas de petróleo se opuseram fortemente a essas metas, buscando, dessa forma, desconstruir os "limites institucionalizados à busca egoísta por seus interesses privados". Não obstante, atualmente, há um consenso de que as metas de conteúdo local são excessivamente ambiciosas. Reconhecendo que isso poderia implicar em custos e atrasos e, em última instância, ameaçar a consecução dos objetivos do "projeto pré-sal" (ALMEIDA, 2013), o governo decidiu diminuir as metas de conteúdo local para os campos de Franco (Cessão Onerosa) e de Libra (partilha). Nesse diapasão, a abordagem das empresas privadas também se tornou mais 
construtiva. Atualmente, elas propõem que as multas pelo não cumprimento das metas de conteúdo local sejam convertidas em investimentos na capacidade instalada da indústria de bens e equipamentos que supre a indústria.

A pressão política das petrolíferas - o que inclui a Petrobras - resultou, também, em que o governo tenha adotado programas como o Brasil Maior ou o Inovapetro, além de uma política industrial voltada para a criação de "clusters de inovação", de forma a fomentar o desenvolvimento da indústria de bens e serviços. Nesse sentido, uma interpretação possível é que a negociação política entre o governo e a indústria atualmente estaria focada em encontrar uma forma melhor de "reorganizar a ordem pública subvertida pelo capitalismo" e de "reconstruir os limites institucionalizados à busca egoísta por interesses privados". Apesar de tudo, ainda havia uma percepção na indústria de que as metas de conteúdo local ainda são muito elevadas, vis-à-vis às arrojadas metas de produção. Mais recentemente, muito em função da grave crise que afeta a indústria de petróleo no Brasil, o Governo optou por flexibilizar as regras de Conteúdo Local ${ }^{17}$.

\section{Política energética, externa e de Comércio Exterior}

Se no tema da política industrial e do conteúdo local, o governo e as petrolíferas têm se aproximado de um consenso - o que sugere a possibilidade de instituições tornarem-se cada vez mais complementares -, o mesmo não pode ser dito em relação à própria política energética. Atualmente, a indústria, na figura do IBP, continua investindo os seus esforços para tentar revogar o artigo 4으 da lei da partilha (12.351/2010), segundo a qual "a Petrobras será a operadora de todos os blocos contratados sob o regime de partilha de produção". Argumentando que a capacidade da Petrobras de operar todos os blocos do pré-sal sob a partilha é insuficiente e de que a existência de múltiplos operadores seria melhor para o país como um todo ${ }^{18}$, as empresas defendem que as rodadas de licitação da partilha permitam que outras empresas operem campos do pré-sal sob o contrato da partilha. Se esse pleito de alterar uma parte da atual política energética/petrolífera brasileira for acolhido, existe uma grande possibilidade de que isso impacte algumas das complementaridades institucionais que o governo procura, aos poucos, formar no setor petróleo. Um bom exemplo é a relação entre a política energética, a externa e a de Comércio Exterior. Como se verá na próxima seção, a política externa brasileira utiliza o petróleo como uma forma de melhorar seus termos de troca internacionais em negociações bilaterais, por exemplo, com a China. Se a regra do operador único for flexibilizada, uma parte proporcionalmente maior do petróleo produzido no pré-sal ficaria à disposição de empresas privadas, que negociariam este petróleo de forma totalmente alheia a um plano estratégico e unificado nacional.

\section{EXISTEM COMPLEMENTARIDADES INSTITUCIONAIS INTERNACIONAIS? O EXEMPLO DAS POLÍTICAS EXTERNA E DE COMÉRCIO EXTERIOR}

O propósito desta última seção é discutir em que medida o conceito de complementaridades institucionais pode ser extrapolado para o contexto internacional. Em outras palavras, até que ponto uma instituição internacional - um regime, uma regulação, uma convenção global etc. - pode possuir uma relação de complementaridade com uma instituição doméstica? Hall e Soskice (2009) argumentam que um país optará por aderir a um regime internacional de acordo com a sua percepção de que essa decisão irá fortalecer as suas vantagens institucionais comparativas nacionais. Havendo essa percepção, infere-se que aquele regime possuiria uma relação de complementaridade institucional com as instituições domésticas. As políticas públicas que exemplificam essa seção são a externa e a de Comércio Exterior. Cabe destacar que, embora o tema tenha sido aludido na seção anterior, na presente seção, a problemática e o método para discuti-lo são diversos.

A descoberta do pré-sal aumentou em muito a importância geopolítica do país, e com isso os graus de liberdade de possibilidades de negociação de política externa no âmbito petrolífero. Para ilustrar este ponto, é particularmente relevante citar a visão de Streeck e Thelen das "instituições como regimes" (Streeck e Thelen, 2009). Estas últimas são regras que visam estipular um padrão de comportamento dos atores sociais e descartar os comportamentos indesejados. Nos regimes, as regras são

\footnotetext{
17 De acordo com notícia da Folha de São Paulo do dia 18/01/2016. Disponível em: <http://www1.folha.uol.com.br/mercado/2016/01/1730845-decretosobre-conteudo-local-agrada-petroleiras-industria-critica.shtml>. Acesso em jan. 2014.

${ }^{18}$ Em 2010, quando o marco regulatório do pré-sal ainda não havia sido aprovado, o IBP contratou o IBRE/FGV para elaborar um estudo - intitulado "Pré-Sal: Potenciais Efeitos do Operador Único" - para embasar teórica e empiricamente a tese que defendia (e que continua defendendo).
} 
estipuladas pelos "formuladores de regras" e obedecidas pelos "tomadores de regras". A definição das instituições como regimes é essencialmente de caráter dinâmico, uma vez que, quando há brechas os "tomadores de regras" buscam interpretar as regras a seu favor ou até mesmo procurar maneiras de burlá-las ${ }^{19}$. Em face disso, os "formuladores de regras" precisam engajar-se continuamente na reformulação das regras, visando a uma melhor adesão por parte dos "tomadores de regras".

Com base nessa definição, interpreta-se que o pré-sal pode redefinir o status do Brasil enquanto "tomador de regras" nos diferentes regimes de negociação de petróleo. Se, nos anos 1970 e 1980, a inserção brasileira no sistema internacional do petróleo era pautada por grandes restrições econômicas, o pré-sal fortalece a capacidade do país de tentar obter melhores contrapartidas para o petróleo que irá exportar. Isto é, embora o Brasil continue sendo um "tomador de regras", sua capacidade de reinterpretar regras a seu favor agora é maior. Nesse contexto, com a mediação da política externa, o país pode escoIher entre o regime internacional que se estabeleceu quando o controle do cartel da OPEP se extinguiu na segunda metade dos anos 1980 e o emergente regime de comercialização ao estilo chinês.

No primeiro desses regimes, a Petrobras continuaria negociando diretamente com uma grande gama de compradores e vendedores, utilizando fórmulas de preços vinculadas a petróleos de referência (PORTO e GUERRA, 2008), sobretudo o Brent. Nessa modalidade de comercialização, o único critério que norteia a compra ou a venda de petróleo ou derivados é a lei dos custos de oportunidade. Assim, a companhia arbitraria entre preços, qualidade e quantidade tanto na condição de compradora como de vendedora. Pautado pela análise neoclássica, este é um regime de comercialização cuja premissa principal é a de que o petróleo é uma commodity como qualquer outra, sem qualquer valor estratégico.

O segundo regime, na realidade, é uma reedição da modalidade de comercialização praticada pelo Brasil nos anos 1970 e 1980 , quando a Petrobras se internacionalizou e passou a importar boa parte do petróleo através do mecanismo de "countertrade"20. Trata-se novamente da possibilidade de atrelar a venda de petróleo a outras negociações comerciais. Mas, diferentemente do que ocorria à época, agora, o principal parceiro comercial passou a ser a China.

Na última década, aquele país tem contribuído para mudar o mapa mundial da comercialização petrolífera. A busca pela segurança energética fez com que os chineses tentassem "compartimentar" o mercado através dos assim chamados "loan-for-oil deals", como explicam Bridge e Le Billon (2012). A interpretação de Lee (2012) é que a China tem procurado "enclausurar" suprimentos de petróleo em países com os quais mantém boas relações diplomáticas. Nesse sentido, desde 2009, Pequim concluiu mais de 12 "loan-for-oil-deals", em que promessas de produção cativa são emitidas em troca de empréstimos. De acordo com Gallagher, Irwin e Koleski (2012), desde 2005, a China forneceu US\$ 86 bilhões em compromissos de empréstimos a países latino americanos, dos quais 69\% em troca de petróleo. Dois desses contratos foram firmados com o Brasil no ano de $2009^{21}$.

\footnotetext{
${ }^{19}$ Eis uma ideia que remete à noção da necessária incompletude dos contratos e das leis, que, em grande parte, decorre da limitada cognição humana. ${ }^{20}$ A Petrobras foi fundada em 1953 com o propósito de importar petróleo e suprir o mercado doméstico com derivados de petróleo porque nas 7 primeiras décadas do século XX, a exploração e produção de petróleo não tinha sido muito bem sucedida no Brasil. Como mostra Felipe (2010, p. 171), no final da década de 1960 e início dos anos 1970, as altas taxas de crescimento do PIB e a expansão das atividades industriais brasileiras aumentaram significativamente o consumo de combustíveis do país. Com o primeiro choque de petróleo de 1973, que reduziu drasticamente a capacidade do país de bancar as suas importações de petróleo e derivados, a Petrobras se lançou em uma campanha para buscar petróleo nas águas rasas da Bacia de Campos. Paralelamente, a empresa passou a se engajar na exploração de petróleo em outros países. Assim, segundo Santos (2009, p. 81), o processo de internacionalização da Petrobras teve início em 1972 quando o Presidente Médici criou a Braspetro, - subsidiária da Petrobras - para explorar petróleo no exterior. Nesse movimento estratégico de internacionalização, a Petrobras pode absorver uma boa parte da tecnologia necessária para aprimorar a exploração em águas rasas no Brasil. Segundo a autora, de 1972 até o ano 2000, a Petrobras atuou em mais de 30 países através da Braspetro, o que incluiu, dentre outros, México, Nigéria, Angola, Iraque, Irã, Argélia, Egito e Colômbia. A partir de 1974 a Braspetro passou a atuar também como uma empresa exportadora autônoma de produtos brasileiros, que passaram a ser trocados pelo petróleo daqueles países. Esse mecanismo de intercâmbio ficou conhecido como "countertrade". Em 1976, foi criada a Interbras, que assumiu a função de comercializar os bens e serviços (ibidem). Dedicando-se somente à exploração e produção de petróleo e gás, e à comercialização de petróleo, a Braspetro intensificou suas atividades, por exemplo, no Iraque. Neste país, a Braspetro teve relativo êxito, sendo responsável em 1976 pela descoberta do campo gigante de Manjoon. Em face das incertezas geopolíticas, a empresa decidiu por abdicar de sua exploração em troca de uma indenização e da garantia da compra do petróleo. Nos anos 1980, o foco da atuação da Braspetro deslocou-se para o Golfo do México e para o Mar do Norte, considerados de menor risco geopolítico. Ao longo de todo o processo de internacionalização da Petrobras e das suas subsidiárias, o Ministério das Relações Exteriores foi um importante parceiro da Petrobras. Estabeleceram-se relações diplomáticas, sobretudo com os países do Oriente Médio, com os quais também se firmaram acordos, e nos quais se estabeleceram embaixadas e para os quais foram enviadas missões diplomáticas.

${ }^{21} \mathrm{O}$ primeiro deles, mediante a assinatura do Memorando de Entendimento sobre Petróleo, Equipamento e Financiamento, que estabeleceu preferência ao fornecimento brasileiro de forma estável e de longo prazo para a China, assegurado por compromisso de financiamento à Petrobras pelo China Development Bank Corporation (CDBC) (BARROS, SCHUTTE e PINTO, 2012, p. 48). Já o segundo foi assinado entre a Petrobras, o CDBC e a China Petroleum \& Chemical Corporation (SINOPEC), onde se estipulou o financiamento de US\$ 10 bilhões por 10 anos do CDBC para a Petrobras. O acordo estipulou que, em 2010, a
} 
Nesse segundo regime de negociações petrolíferas, uma importante premissa é que o petróleo é um recurso energético fortemente "geopolitizado" (BRITO, SANTOS, ROUSSEAU et al., 2012). Em outras palavras, o petróleo não é uma commodity como outra qualquer, mas um "bem estratégico" (BRIDGE e LE BILLON, 2012). De acordo com Altvater (2010, p. 259), os “custos da extração não são determinados apenas pelas condições geológicas de uma jazida, mas também pelas relações sociais e políticas". Na visão de Labban (2010), a escassez de petróleo cada vez mais é resultado do monopólio dos Estados sobre a extração e o acesso às reservas. Nesse sentido, como mostra Altvater (2010, p. 259), nem "os neoliberais conservadores do establishment norte-americano, obcecados pelo poder, (...) confiam nos mecanismos geoeconômicos da oferta e da demanda. Por um lado, pregam o mercado; por outro, implementam uma geopolítica rigorosa, que também não tem escrúpulos em recorrer às ações militares."

A partir dessa leitura, a Diplomacia Brasileira tem se esforçado para atrelar a venda do petróleo brasileiro à China a uma série de contrapartidas tecnológicas e comerciais, como a instalação de fábricas com conteúdo tecnológico avançado por parte dos chineses, a compra de etanol, o auxílio ao desenvolvimento de Refinarias Premium no Brasil ${ }^{22}$, ou até a entrada de empresas chinesas no consórcio do pré-sal.

Com base nesses elementos, a visão de Crouch (2009) acerca das complementaridades institucionais internacionais e a Teoria da Regulação apresentam elementos mais adequados para compreender como o Brasil poderia, possivelmente, tentar criar complementaridades institucionais com os diferentes regimes de comercialização de petróleo no mundo.

O primeiro autor parte do diagnóstico de que uma análise da eficiência institucional das variedades de capitalismo, na verdade, é, em grande parte, incompleta no atual estágio do capitalismo globalizado, já que é muito difícil traçar uma fronteira clara entre o que é exógeno e o que é endógeno à economia. O exemplo das firmas é particularmente elucidativo para esse ponto. Fazendo referência às relações das firmas com as 5 esferas institucionais da literatura das variedades de capitalismo de Hall e Soskice (2009), tem-se que, cada vez mais, estas se relacionam com atores - fornecedores, empregados, concorrentes governos - sediados em outros países. Visando a todo tempo obter maior lucratividade - seja para burlar o pagamento de impostos ou para servir-se de recursos humanos e naturais mais baratos -, cada vez mais, as firmas extrapolam as fronteiras nacionais. Esse expediente tem sido utilizado, por exemplo, pela Petrobras, que usa uma afiliada na Holanda para baratear os seus custos de capital.

Por sua vez, a Teoria da Regulação também possui uma série de características que também justificam o seu uso como instrumental teórico para compreender como o Brasil pode formar complementaridades institucionais internacionais com os diferentes regimes de comercialização de petróleo. A principal razão para isso é que, na perspectiva de Boyer (2005), por uma série de motivos, os países combinam, em diferentes proporções, os diversos mecanismos de coordenação que existem: além de firmas e estados, também as comunidades, as redes, as associações e os regimes. Em suma, as firmas não são os únicos mecanismos de coordenação considerados por Boyer (2005). Em outro trabalho, Boyer (2009) considera que um dos cinco modos institucionais que se agrupam para configurar diferentes modos de regulação ${ }^{23}$ - que, por sua vez - regulam os tipos de regimes de acumulação ${ }^{24}$-, é a "inserção internacional". Assim, na perspectiva de Boyer (2009), o modo institucional "inserção internacional" precisa ser coordenado com os outros 4: relação salarial, formas de concorrência, relação monetária e Estado. Outra vantagem da Teoria da Regulação, em especial nos escritos de Jessop (2005; 2008) e de O’Hara (2000), em grande parte influenciados pelo Marxismo, é que se admite que os atores administram não o equilíbrio entre as instituições, mas sim o dissenso e o conflito, que também são inerentes a elas.

Informando a nossa análise também com a visão de Crouch (2009) e com diferentes autores da Teoria da Regulação - e não somente com a literatura das Variedades de Capitalismo -, temos que as negociações comerciais internacionais envolvendo o

\footnotetext{
Petrobras oferecesse, obrigatoriamente, à sua contraparte chinesa a primeira opção para a compra diária dos volumes mencionados. Nos 9 anos seguintes, esse volume aumentou para 200.000 barris diários.

${ }^{22}$ Conforme a Ata da Terceira Reunião da Comissão Sino-Brasileira de Alto Nível de Concertação e Cooperação (COSBAN), que ocorreu em 6 de novembro de 2013 na cidade de Cantão.

${ }^{23}$ Boyer (2009) aponta 7 distintos modos de regulação, mas admite a existência de outros, dependendo da maneira como se agrupam os modos institucionais: regulação à moda antiga, regulação típica do século XIX, regulação do período entre-guerras, regulação monopolista do pós-guerra, regulação do acirramento da concorrência, regulação dominada pela terceirização, regulação dominada pela "financeirização".

${ }^{24}$ Os indicados por Boyer (2009) são: regulação extensiva com regulação da concorrência - relativo à Inglaterra do século XIX -, regulação intensiva sem consumo de massa - relativo ao período entre guerras -, regulação intensiva com consumo de massa - fordismo -, regulação com aprofundamento das desigualdades - o modelo atual.
} 
petróleo estão longe de serem um jogo de "ganha-ganha" que tende ao equilíbrio. Ao aceitar que, em algumas situações, as negociações servem para reduzir danos, muitas vezes se constata que as complementaridades institucionais são, no máximo, algo efêmero e temporário. Diante disso, para resguardar-se das intempéries do mercado internacional de petróleo e derivados, talvez a estratégia mais cautelosa para o Brasil seja não ater-se a uma única estratégia de comercialização, mas sim, diversificar a base de compradores (BRITO, SANTOS, ROUSSEAU et al., 2012). Mais além, diante da extrema volatilidade dos preços internacionais do petróleo e da existência de mecanismos de hedge nesses mercados, a estratégia petrolífera do país não pode prescindir de uma forte vertente financeira (securitização).

\section{CONCLUSÕES}

O objetivo desse artigo foi analisar a política petrolífera brasileira e, mais especificamente, a viabilidade do "projeto pré-sal" (ALMEIDA, 2013), à luz da literatura das variedades de capitalismo, com especial ênfase para o conceito de "complementaridades institucionais", que é fundamental nessa vertente teórica.

Constatou-se que a política petrolífera brasileira, na realidade, é uma coletânea de políticas públicas específicas que compreende: energética, ambiental, macroeconômica, industrial, educacional (de recursos humanos), tecnológica, defesa, externa, regulatória, de logística (sobretudo portuária), tributária, de Comércio Exterior e de financiamento. Diante do desafio imposto pelo "projeto pré-sal", essas políticas têm passado e continuarão passando por um processo de reavaliação e redimensionamento para que possam ser executadas em uma escala mais adequada. Em muitos dos casos, esse processo ocorre em simultâneo, de forma que duas ou mais políticas são reavaliadas e redimensionadas de forma conjunta. Assim, nas múltiplas interseções que existem entre as referidas políticas - por exemplo, energética e ambiental -, avalia-se se suas respectivas metas e instrumentos são compatíveis.

Argumentou-se que esse processo pode ser interpretado como uma busca por "complementaridades institucionais". Em outras palavras, os policy makers tendem a tomar iniciativas visando a criar e/ou aumentar as sinergias entre as políticas, de forma que estas "aumentem seus retornos" de forma recíproca, em linha com Hall e Soskice (2009). Para tal, seguiu-se o entendimento de North (1991), Pierson (2006) e Fiani (2013) de que políticas podem ser interpretadas como instituições. No entanto, o argumento desenvolvido ao longo do artigo não se ateve somente à definição de Hall e Soskice (2009) do que são e como se formam as "complementaridades institucionais".

Nas duas primeiras duas seções, procurou-se descrever os principais traços da literatura das variedades de capitalismo (Seção I) e analisar como esta se aplica ao caso brasileiro (Seção II). Já na terceira, buscou-se descrever o processo de formação de uma dessas complementaridades institucionais, a que passou a existir entre a política energética e a de política ambiental (licenciamento ambiental). Foi argumentado que o surgimento dessa complementaridade institucional é muito bem descrito pela perspectiva dos sistemas abertos de Becker (2007) e pela modalidade de mudança institucional que Streeck e Thelen (2009) chamam de "layering", ou "estratificação".

Na seção seguinte, analisou-se o caso de outras duas "complementaridades institucionais" entre políticas que fogem à compreensão de Hall e Soskice (2009). A perspectiva de Crouch (2009) acerca das "complementaridades institucionais", segundo o qual é, empiricamente, muito mais relevante falar em instituições complementares quando uma instituição mais forte apoia uma mais fraca, foi bastante elucidativa para descrever a relação entre a política energética e a política de financiamento da Petrobras: através da sua força financeira, o Estado brasileiro apoiou a Petrobras, capitalizando-a através da "cessão onerosa". Já o entendimento de Amable (2009) de que existem "complementaridades institucionais dinâmicas" foi bastante útil para descrever como as demandas por políticas públicas de atores estratégicos como a Petrobras são capazes de "moldar" políticas públicas, em claro benefício desses últimos. Nessa seção, o olhar recaiu sobre a política educacional do país.

Com base no exemplo da relação de dependência entre a política energética e a macroeconômica, na quinta seção analisouse como, em alguns casos, a ausência de "complementaridades institucionais" - que pode ser o produto do conflito entre atores estratégicos dentro e fora da burocracia - pode, em um caso extremo, comprometer a viabilidade do "projeto présal". Essa seção foi embasada teoricamente pela perspectiva de Peck e Theodore (2007) acerca das complementaridades institucionais e pela visão de Streeck (2012) de como funciona a política no capitalismo. Em primeiro lugar, constatou-se que 
há um perigoso descasamento entre os objetivos da política macroeconômica brasileira e o "projeto pré-sal". Mais à frente, constatou-se que a hibridização do setor petrolífero brasileiro - resultado das mudanças institucionais dos anos 1990 - permitiu a determinados atores estratégicos na indústria, sobretudo às empresas privadas, opor-se politicamente às decisões governamentais para o setor. Se, no caso da política industrial, a atuação política desses novos atores estratégicos pode contribuir, até certo ponto, para o sucesso do "projeto pré-sal", no caso das políticas energética e externa, argumentou-se que os planos das agências e governamentais de implementar certas "complementaridades institucionais" foi posto em xeque.

Finalmente, na última seção, tentou-se analisar em que medida podem existir "complementaridades institucionais" entre uma instituição doméstica e uma internacional. Verificou-se que ao aceder a um regime internacional de comercialização de petróleo - através da mediação da Política Externa - em determinadas circunstâncias uma instituição internacional pode aumentar o retorno de uma política pública doméstica, como a de Comércio Exterior. No entanto, ao aludir à perspectiva de Crouch (2009) - para o qual a literatura das variedades de capitalismo não se encontra bem equipada para compreender a dinâmica desestabilizadora da globalização -, e à Teoria da Regulação, constatou-se que, na realidade, o regime de comercialização de óleo e derivados mais voltado para o mercado, ou o regime de comercialização ao estilo chinês, tendem a complementar a política de Comércio Exterior, na melhor das hipóteses, de forma efêmera e temporária. Assim, sobretudo no cenário internacional, as instituições domésticas tendem a administrar o conflito e o dissenso.

Com base na análise precedente, em que investigamos como diferentes tipos de "complementaridades institucionais" são formadas entre as políticas públicas que integram o complexo de políticas do "projeto pré-sal", a conclusão a que chegamos é que, muito provavelmente, o Estado brasileiro possui os recursos materiais, organizacionais e institucionais para viabilizar esse projeto, em linha com a hipótese de que, quanto mais complementaridades institucionais existirem entre as políticas que compõem o "projeto pré-sal", maior a propensão ao seu sucesso. Neste sentido, os desdobramentos políticos e econômicos da Operação Lava Jato e a queda dos preços do petróleo em 2014/2015, os quais interpretamos como "choques exógenos" que irão afetar temporariamente a busca por complementaridades institucionais, não irão inviabilizar definitivamente a consecução do "projeto pré-sal".

Chegando ao último parágrafo deste artigo, ressalta-se que, para o estudo das políticas públicas, é muito importante perceber que as instituições, em muitos casos, administram o conflito e o dissenso, e não situações de calmaria. Esta é, em última análise, a perspectiva teórica alternativa para o estudo das políticas públicas a qual este autor gostaria de aludir. A indústria do petróleo é, ao mesmo tempo, extremamente lucrativa e volátil. Assim, administrar o "bilhete dourado" que é prometido pelo "projeto pré-sal" não é um desafio trivial à policy-making. Invariavelmente, interesses econômicos e políticos investidos farão com que atores estratégicos - dentro e fora da burocracia - mobilizem capital institucional, político e econômico para tumultuar a aparente placidez dos "ciclos da política pública". Nesse sentido, em linha com Almeida (2013), a única alternativa que resta é mobilizar todo o capital político possível junto aos atores estratégicos dentro e fora da burocracia para formar consensos e dirimir os conflitos que aparentam ser insolúveis. Em última análise, a consecução dos objetivos do "projeto pré-sal" é uma prova de fogo a que Diniz $(1995 ; 1996)$ chama de "coordenação" e "interlocução"; em outras palavras, à capacidade do Estado valer seus interesses em relação a atores estratégicos que atuam dentro e fora da burocracia. 


\section{REFERÊNCIAS}

ALBERT, M. Capitalism Against Capitalism. London: Whurr, 1993.

ALMEIDA. E. L. F. Desafios do setor de petróleo brasileiro. Blog Infopetro. Disponível em:<http://infopetro.wordpress.com>. Acessado em: 5 de agosto de 2013.

ALTVATER, E. O fim do capitalismo como o conhecemos. Editora Civilização Brasileira: Rio de Janeiro, 2010.

ALVEAL, C. Os desbravadores: a Petrobrás e a construção do Brasil industrial. Rio de Janeiro: Relume Dumará, 1993.

ALVEAL, C. $\mathbf{5 0}$ anos da Petrobras: O Triunfo Real do Potencial Brasileiro. In: BICALHO, R. (Org.). Ensaios Sobre Política Energética. Rio de Janeiro: Editora Interciência, 2007. 22-26 p.

AMABLE, B. The diversity of modern capitalism. Oxford: Oxford University Press, 2009.

AMSDEN, A. Escape from empire. Cambridge: MIT Press, 2007.

BARROS, P. B.; SCHUTTE, G. R.; PINTO, L. F. S. Além da Autosuficiência: o Brasil como protagonista no setor energético. IPEA. Texto para Discussão no 1725, abril de 2012.

BECKER, U. Open systemness and contested reference frames and change. A reformulation of the varieties of capitalism theory. SocioEconomic Review, v. 5, n. 2, p. 261-286, 2007.

BICALHO, R. O pré-sal e o controle do Estado. Blog Infopetro, 22/11/2010. Disponível em: <http://infopetro.wordpress.com>. Acessado em: fevereiro de 2012.

BOYER, R. How and Why Capitalisms Differ. MPIfG Discussion Paper 05/4, 2005. Disponível em: <http://www.mpifg.de/pu/dp09-13_ de.asp>. Acessado em: 5 de janeiro de 2014.

BOYER, R. Teoria da Regulação. São Paulo: Estação Liberdade, 2009.

BRASIL. Lei no 12.351, de 22 de dezembro de 2010. Dispõe sobre a exploração e a produção de petróleo, de gás natural e de outros hidrocarbonetos fluidos, sob o regime de partilha de produção, em áreas do pré-sal e em áreas estratégicas; cria o Fundo Social - FS e dispõe sobre sua estrutura e fontes de recursos; altera dispositivos da Lei no 9.478, de 6 de agosto de 1997; e dá outras providências. Lex: Diário Oficial [da República Federativa do Brasil], Brasília, 2010. Disponível em < http://www.planalto.gov.br/ccivil_03/_Ato2007-2010/2010/Lei/L12351.htm>. Acessado em 25 de fevereiro de 2012.

BRIDGE, G.; LE BILLON, P. Oil. Cambridge: Polity, 2013.

BRITO, T. L. F.; DOS SANTOS, E. M.; ROUSSEAU, I.; NAVA, P. C. A dialética da segurança energética e a interdependência das nações. In: MONIÉ, F.; BINSZTOK, J. (Org.). Geografia e geopolítica do petróleo. Rio de Janeiro: Mauadx, 2012. 15-50 p.

BUSCH, A. Wirtschaftsmacht Brasilien. München: Karl Hanser Verlag, 2009.

CHANG, H. J. Chutando a Escada: A estratégia do desenvolvimento em perspectiva histórica. São Paulo: UNESP, 2004.

CHANG, H. J. Maus Samaritanos. Rio de Janeiro: Elsevier, 2008.
CHANG, H. J. Hamlet without the Prince of Denmark: How development has disappeared from today's 'development' discourse. In.: KHAN, S.; CHRISTIANSEN, J. (org.). Towards New Developmentalism: Market as Means rather than Master. Abingdon: Routledge, 2010.

CROUCH, C. Typologies of Capitalism. In. HANCKÉ, B. (Org.). Debating Varieties of Capitalism. New York: Oxford University Press, 2009. 75-94 p.

DINIZ, E. Governabilidade, Democracia e Reforma do Estado: Os Desafios da Construção de uma Nova Ordem no Brasil dos anos 90. Dados - Revista de Ciências Sociais, Rio de Janeiro, v. 38, n. 3, p. 385-415, 1995.

DINIZ, E. Governabilidade, governance e reforma do Estado: considerações sobre o novo paradigma. Revista do Serviço Público, v. 47, n. 1, p. 67-82, mai./ago. 1996.

DINIZ, E. O Pós-Consenso de Washington: globalização, Estado e governabilidade reexaminados. In: DINIZ, E. (Org.). Globalização, Estado e Desenvolvimento. Rio de Janeiro: FGV, 2007.

DINIZ, E. Estado, Variedades de Capitalismo e Desenvolvimento em Países Emergentes. Desenvolvimento em debate, v. 1, n. 1, p. 7-27, jan./abr. 2010b.

ESPING-ANDERSEN, G. The Three Worlds of Welfare Capitalism. Princeton, Princeton University Press, 1990.

EVANS, P. A tríplice aliança. Rio de Janeiro: Zahar, 1979.

EVANS, P. Autonomia e parceria. Rio de Janeiro: Editora UFRJ, 2001.

EVANS, P. Extending the 'Institutional' Turn. World Institute for Development Economics Research Research Paper n. 113, Outubro de 2006.

EVANS, P. In Search of the 21st Century Developmental State. The Centre for Global Political Economy. University of Sussex. UK. Working Paper n. 4, 2008.

FELIPE, E. S. Mudanças institucionais e estratégias empresariais: a trajetória e o crescimento da Petrobras a partir da sua atuação no novo ambiente competitivo (1997-2000). 2010. 322 f. Tese (Doutorado em Economia) - Instituto de Economia, Universidade Federal do Rio de Janeiro, Rio de Janeiro. 2010.

FIANI, R. Arranjos Institucionais e Desenvolvimento: o Papel da Coordenação em Estruturas Híbridas. Textos Para Discussão IPEA no 1815, Rio de Janeiro, março de 2013.

FLIGSTEIN, N. The Architecture of Markets. Princeton: Princeton University Press, 2001.

FRANKE, M. Petróleo tem futuro no Brasil mas é preciso mudar. Rio de Janeiro: McKlausen, 1993.

GALLAGHER, K. P.; IRWIN, A.; KOLESKI, K. The New Banks in Town: Chinese Finance in Latin America. Inter-American Dialogue, fevereiro de 2012.

HAAS, P. M. Knowledge, Power and International Policy Coordination. Columbia: University of South Carolina Press, 1997. 
HALL, P.; SOSKICE, D. An Introduction to Varieties of Capitalism. In. HANCKÉ, B. (Org). Debating Varieties of Capitalism. New York: Oxford University Press, 2009. 21- 74 p.

HANCKÉ, B. Introducing the debate. In. HANCKÉ, B. (Org.). Debating Varieties of Capitalism. New York: Oxford University Press, 2009. 1-17 p.

HAY, C.; LISTER, M.; MARSH, D. (Eds.). The State: Theories and Issues. Basingstoke: Palgrave MacMillan, 2005. 98-117 p.

HERNANDEZ-PEREZ, A. Economics of oil regulation and the Brazilian reform: Some issues. Energy Policy, v. 39, n. 1, p. 57-65, 2011.

HOLLINGSWORTH, J. R.; BOYER, R. Coordination of Economic Actors and Social Systems of Production. In: HOLLINGSWORTH, J. R.; BOYER, R. (Org.). Contemporary Capitalism: the Embeddness of Institutions. New York: Cambridge, University Press, 1997. 1-48 p.

HOWLETT, M.; RAMESH, M.; PERL, A. Política Pública. Rio de Janeiro: Elsevier, 2013.

IEA. World Energy Outlook. Paris: OECD/IEA, 2013.

IOOTTY, M. et al. Projeto PIB: Perspectivas de Investimento em Energia: Documento Setorial Petróleo. Documento não editorado. Dezembro de 2008.

JACKSON, G.; DEEG, R. How Many Varieties of Capitalism? Comparing the Comparative Institutional Analyses of Capitalist Diversity. MPIfG Discussion Paper 06/2, 2006. Disponível em: <http://www.mpifg.de/ pu/dp03-07_de.asp>. Acessado em: 08 jan. 2014.

JESSOP, B. The Future of the Capitalist State. Cambridge: Polity, 2005.

JESSOP, B. State Power. Cambridge: Polity Press, 2008.

KERSTENETZKY, C. L. O Estado do Bem-Estar Social na Idade da Razão. Rio de Janeiro: Elsevier, 2012.

LABBAN, M. Space, Oil and Capital. London: Routledge, 2010.

LEE, J. China's Geostrategic Search for Oil. Center for Strategic and International Studies, The Washington Quarterly, v. 35, n. 3, p. 75-92, 2012.

LEITE, A. D. A Energia do Brasil. Rio de Janeiro: Campus, 2007.

LEOPOLDI, M. A. P.; MANCUSO, W. P.; IGLECIAS, W. Estado, empresariado e desenvolvimento no Brasil: reflexões sobre o período pós-neoliberal. In: LEOPOLDI, M. A. P.; MANCUSO, W. P.; IGLECIAS, W. Estado, empresariado e desenvolvimento no Brasil. São Paulo: Editora de Cultura, 2010. 15-33 p.

LISTER, M.; MARSH, D. Conclusion. In: HAY, C.; LISTER, M.; MARSH, D. (Eds.). The State: Theories and Issues. Basingstoke: Palgrave MacMillan, 2005. 248-260 p.

MARIANO, J. B. Proposta de Metodologia de Avaliação Integrada de Riscos e Impactos Ambientais para Estudos de Avaliação Ambiental Estratégica do Setor de Petróleo e Gás Natural em Áreas Offshore. 2007. 592 f. Tese (Doutorado em Planejamento Energético) - COPPE Universidade Federal do Rio de Janeiro. Rio de Janeiro, 2007.

MORGAN, G. Introduction. In: MORGAN, G.; WHITLEY, R.; MOEN, E. Changing Capitalisms? Complementarities, Contradictions and Capability Development in an International Context. Oxford: Oxford University Press, 2005.
NADAL, A. Macroeconomics for sustainability. London: Zed Books, 2011.

NORTH, D. C. Institutions. The Journal of Economic Perspectives, v. 5, n. 1, p. 97-112. 1991.

O'HARA, P. A. Marx, Veblen and Contemporary Institutional Political Economy. Cheltenham: Edward Elgar, 2000.

PECK, J.; THEODORE, N. Variegated Capitalism. Progress in Human Geography, n. 21, p. 731-772, 2007.

PIERSON, P. Public policies as institutions. In: SHAPIRO, I.; SKOWRONEK, G. D. Rethinking political institutions: the art of the state. New York: New York University Press, 2006.

PINTO JR., H. Q. (Org.). Economia da Energia. Rio de Janeiro: Campus, 2007.

PORTO, A. E. C.; GUERRA, L. C. T. Comércio internacional de petróleo e derivados. Interciência: Rio de Janeiro, 2008.

QUINTANS, L. C. P. Direito do Petróleo - Conteúdo Local. Rio de Janeiro: Freitas Bastos Editora, 2010.

REINERT, E. How Rich Countries Got Rich ... and Why Poor Countries Stay Poor. New York: Carroll \& Graf Publishers, 2007.

RODRIK. D. The Globalization Paradox. London: Norton, 2011.

SANTOS, R. M. N. Petrobras en la política exterior del gobierno de Lula: una mirada desde la Economía Política Internacional. 2009. 241 f. Dissertação (Mestrado em Relações e Negociações Internacionais) - Facultad Latinoamericana de Ciencias Sociales (FLACSO/Argentina) e Universidad de San Andrés em cooperação com a Universidad de Barcelona, Buenos Aires. 2009.

SARAVIA, E. Introdução à teoria da política pública. In: SARAVIA, E.; FERRAREZI, E. Políticas Públicas: Coletânea. Brasília: ENAP, 2006. 21-42 p.

SCHMIDT, V. Bringing the State Back Into the Varieties of Capitalism And Discourse Back Into the Explanation of Change. Program for the Study of Germany and Europe Working Paper Series 07.3, publicado em 2007.

SERRANO, F.; SUMMA, R. A desaceleração rudimentar da economia brasileira desde 2011. OIKOS, v. 11, n. 2, p.166-202, 2012.

SOUSA, F. J. R. A Cessão Onerosa do pré-sal e a capitalização da Petrobras. Câmara dos Deputados. Estudo, fevereiro/2011.

STIGLITZ, J. Freefall. New York: Norton, 2010.

STREECK, W. E Pluribus Unum? Varieties and Commonalities of Capitalism. MPIfG Discussion Paper 10/12, 2010a. Disponível em: <http://www.mpifg.de/pu/dp09-13_de.asp>. Acessado em: 10 jan. 2014.

STREECK, W. Institutions in History: Bringing Capitalism Back in. In: MORGAN, G. et al. (Eds.). In: The Oxford Handbook of Comparative Institutional Political Analysis. Oxford: Oxford University Press, 2012a. 659-686 p.

STREECK, W.; THELEN, K. Institutional Change in Advanced Political Economies. In: HANCKÉ, B. (Org.). Debating Varieties of Capitalism. New York: Oxford University Press 2009. 95-131 p. 
TEIXEIRA, I. M. V. O Uso da Avaliação Ambiental Estratégica no Planejamento da Oferta de Blocos para Exploração e Produção de Petróleo e Gás Natural no Brasil: uma proposta. 2008. 302 f. Tese (Doutorado em Planejamento Energético) - COPPE Universidade Federal do Rio de Janeiro. Rio de Janeiro, 2008.

TOLMASQUIM, M. T.; PINTO Jr., H. Q. (Org.). Marcos regulatórios da indústria mundial do petróleo. Rio de Janeiro: Synergia, 2011.
VAN DER PIJL, K. A Survey of Global Political Economy. Centre for Global Political Economy - University of Sussex. Versão 2.1, Outubro de 2009.

WEISS, L. The myth of the powerless state. Ithaca: Cornell University Press, 1998.

WHITLEY, R. Divergent Capitalisms: The Social Structuring and Change of Business Systems. Oxford: Oxford University Press, 1999. 